\title{
Working
}

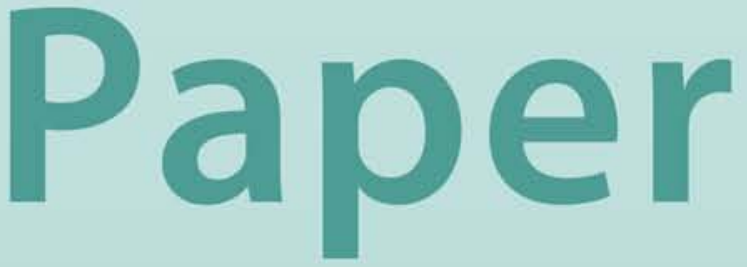




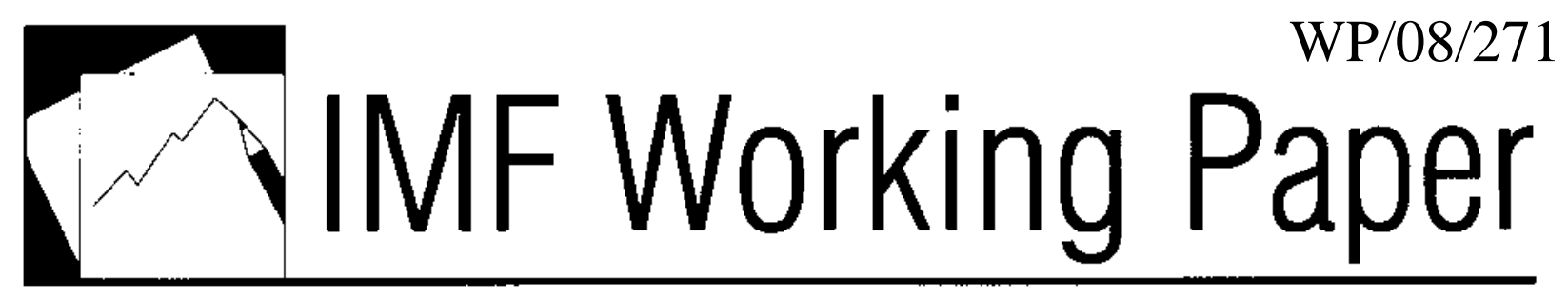

\section{Analyzing Determinants of Inflation When There Are Data Limitations: \\ The Case of Sierra Leone}

Jan Gottschalk, Kadima Kalonji, and Ken Miyajima 


\title{
IMF Working Paper
}

\author{
African Department \\ Analyzing Determinants of Inflation When There Are Data Limitation: \\ The Case of Sierra Leone \\ Prepared by Jan Gottschalk, Kadima Kalonji, and Ken Miyajima \\ Authorized for distribution by Brian Ames
}

December 2008

\begin{abstract}
This Working Paper should not be reported as representing the views of the IMF. The views expressed in this Working Paper are those of the authors and do not necessarily represent those of the IMF or IMF policy. Working Papers describe research in progress by the authors and are published to elicit comments and to further debate.
\end{abstract}

This paper examines the determinants of inflation in Sierra Leone using a structural vector autoregression (VAR) approach to help forecast inflation for operational purposes. Despite data limitations, the paper accurately models inflation in Sierra Leone. As economic theory predicts, domestic inflation is found to increase with higher oil prices, higher money supply, and nominal exchange rate depreciation. The paper then employs a historical decomposition approach to pinpoint the sources of a marked decline in inflation in 2006 and assesses its forecasting properties. Overall, the model serves as a useful addition to the toolkit for analyzing and forecasting inflation in countries with limited data availability.

JEL Classification Numbers:E31, E37, O55

Keywords: Historical decomposition, impulse response, inflation, variance decomposition, vector autoregression (VAR)

Author’s E-Mail Address:jgottschalk@imf.org, kkalonji@imf.org, kmiyajima@imf.org 


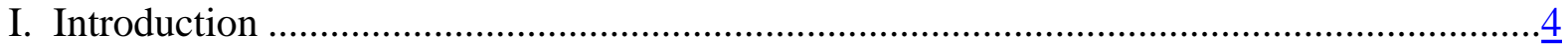

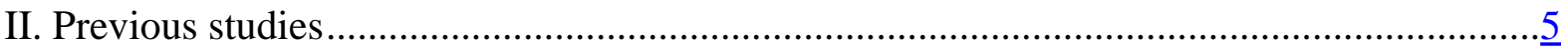

A. Inflation in Sierra Leone ...............................................................................

B. Vector Autoregression............................................................................................

III. Modeling inflation in sierra leone.............................................................................

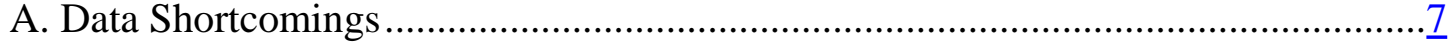

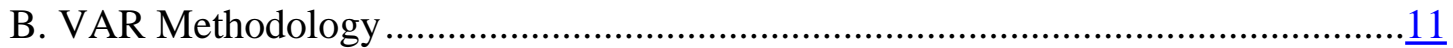

C. Empirical Model for Sierra Leone ................................................................14

D. Estimation Results............................................................................................

IV. Analyzing causes of inflation and forecasting inflation ...................................................

A. Analyzing the Decline in Inflation in 2006...........................................................

B. Forecasting Inflation for 2007 ..........................................................................31

C. Forecasting Medium-term Inflation .......................................................................

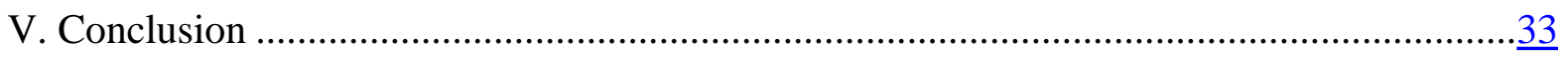

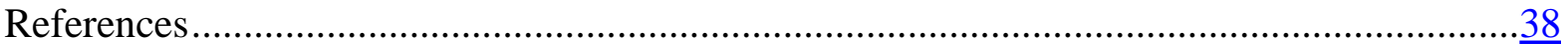

Tables

1. Sierra Leone: Results for the Variance Decomposition..................................................

Figures

1. Sierra Leone: CPI Index and Its Determinants ………………................................

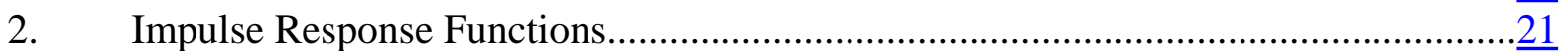

3. Historical Decomposition of Inflation in Sierra Leone, 2002-06 ..............................28

4. Contribution of the Individual Structural Shocks ...................................................30

5. $\quad$ Out-of-Sample Inflation Forecast (model estimated until end-2006 .............................31

6. Inflation Model up to December 2007 …………...................................................

7. $\quad$ Out-of-Sample Inflation Forecast (model estimated until end-2007)............................33

\section{Boxes}

1. Sierra Leone: Monetary and Fiscal Policy Coordination..............................................10

2. Sierra Leone: Pass-through of Oil Prices and Exchange Rates .....................................24

Appendix Tables

1. VAR Residual Serial Correlation LM Tests ..............................................................37

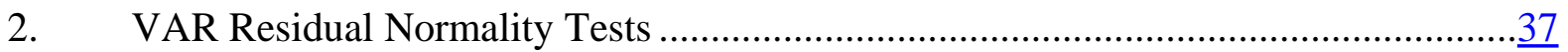

3. White Residual Heteroskedestacity Tests ................................................................... 
Appendix Figures

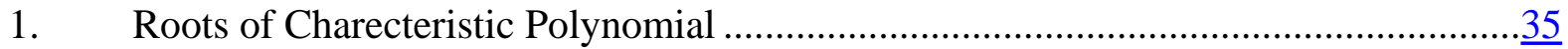

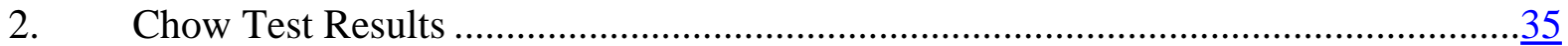

3. Cumulative Impulse Response Functions ................................................................. 


\section{INTRODUCTION ${ }^{1}$}

Understanding inflation dynamics is critical to the design of Fund programs to help stabilize economies. In many low-income countries, lack of data, particularly for the real sector, hampers inflation analysis. This paper presents a small vector autoregression (VAR) model for inflation that can be used for forecasting inflation and analyzing its causes while using only widely available nominal data and exchange rates. The model has been estimated for Sierra Leone, where inflation has been a particular challenge and data shortcomings are severe. The country suffered double-digit rates during the long period of conflict and, after a brief decline as the conflict was ending in 2000, persistent inflation above 10 percent starting in 2003. Data limitations arise because of civil conflict—which introduces a severe structural break in the data, restricting analysis to the post-conflict period-and the lack of statistical capacity, especially regarding the collection of real sector data.

The paper uses the inflation model for three purposes: (i) it analyzes the causes of a sharp decline in inflation in the second half of 2006; (ii) generates an out-of-sample forecast for 2007 and evaluate it against inflation developments in 2007; and (iii) generatse a mediumterm out-of-sample forecast for 2008-10. For the first task, the historical decomposition technique of VARs is used; to simulate a real-time analysis, the sample period is truncated at end-2006. The truncated sample period is also used for generating the out-of-sample forecast for 2007, the second task. The medium-term forecast, the third task, is based on the fullsample model with data until end 2007.

Section II reviews the literature to set this study in context. Section III discusses the VAR methodology, the specification of the model for Sierra Leone, and estimation results. Section IV then utilizes the model for the three tasks described above. Section V draws conclusions.

\footnotetext{
${ }^{1}$ This paper benefited from helpful comments from Alfredo Cuevas, Norbert Funke, Issouf Samake, and Norbert Toé.
} 


\section{Previous Studies}

\section{A. Inflation in Sierra Leone}

Kallon (1994) estimates a structural equation for inflation using two-stage least squares based on data spanning 1967 Q1-1987 Q4. Variables are growth of narrow money, growth of real government expenditure, real GNP growth, import price inflation, percentage change in the treasury bill rate, change in the interest rate differential, and inflation expectations. ${ }^{2}$ He finds that money growth tends to raise inflation-a 1 percent increase in money growth would lead to a $1 / 2$ percent increase in inflation over four quarters and 1.3 percent in the long run. ${ }^{3}$ Real GDP growth also is found to lead to higher inflation, as do expectations of higher inflation. In contrast, inflation is found to be insensitive to import price inflation or increases in government expenditures. Kallon therefore concludes that to counter inflation the authorities should use monetary restraint and other aggregate demand policies.

Tucker (2004) uses cointegrating VAR to find a long-run stability of money demand in Sierra Leone as part of the West African Monetary Zone. ${ }^{4}$ Using data for 1981 Q1-2000 Q4, he examines the relationship between real broad money balance, real GDP, three-month deposit rates, three-month treasury bill discount rates, and inflation. ${ }^{5}$ He finds that the relationship between money balance, real GDP, and T-bill rates was stable in the long run and concludes that the proposed West African Central Bank could conduct a single monetary policy to achieve price stability within the zone. ${ }^{6}$

\footnotetext{
${ }^{2}$ Inflation expectations are estimated based on the rational expectations hypothesis, the adaptive expectations hypothesis, and a standard autoregressive moving average.

${ }^{3}$ This requires a 1 percent increase in money growth in all four quarters.

${ }^{4}$ Including the Gambia, Ghana, Nigeria, and Sierra Leone. Guinea and Liberia were excluded due to data constraints.

${ }^{5}$ Inflation is used as a proxy for the return on real assets. Tucker (2004) also includes dummies for seasonality and economic reforms.

${ }^{6}$ He adds that open market operations should be accompanied by financial market development and increased private sector participation to make monetary policy more effective.
} 
Using highly disaggregated price data, Kovanen (2006) estimates cross-section and timeseries regressions to characterize inflation dynamics in Sierra Leone. Consistent with other literature on inflation persistence, he finds inflation is less persistent in Sierra Leone than in mature economies. He also finds that price changes are frequent due to uncertainty about inflation and the generally low value-added content of domestic products. Combined with the finding that the fraction of items subject to price changes tends to be very high and volatile in Sierra Leone, Kovanen concludes that the timing of repricing tends to be state-dependent, whereas in mature economies it tends to be predetermined. He also concludes that the reduction of monetary surprises and supply constraints would help reduce the fraction of items being repriced and the frequency of repricing, thus reducing the level and volatility of inflation.

In general the literature suggests that monetary policy - both through the direct effect of money growth and indirectly through inflation expectations - is important for inflation, as are supply side factors. This helps us with the choice of variables for our models. Since the VAR methodology has not yet been applied for modeling inflation dynamics in Sierra Leone, our model complements the literature.

\section{B. Vector Autoregression}

Ever since Sims $(1972,1980)$ originated the VAR approach, it has been the standard tool for examining the monetary transmission mechanism, leading, e.g., to seminal work for the U.S. by Christiano, Eichenbaum, and Evans (1998). The VAR approach was originally developed in the context of a closed economy, but increasingly has been extended to model open economies. In the process, the range of variables has been expanded to capture external shocks. For instance, Stavrev (2005) uses the current account balance; Catalan and Lama (2006) use the terms of trade, current account, and real exchange rate; Kuijs (2002) and Mwase (2006) use the nominal exchange rate; and Cheng (2006) uses a country-specific commodity price index, international oil prices, and the US Federal funds rate. Variable choices for Sierra Leone draws on these precedents but are limited by data availability regarding both the type of data available and the length of available time series, mainly because of Sierra Leone's history of civil war. 


\section{Modeling INFLATION IN SiERRA LEONE}

\section{A. Data Shortcomings}

Lack of data is a major constraint for modeling the process of inflation in Sierra Leone. Because the interruption of economic activity by civil war in the 1990s likely led to several structural breaks and interrupted the process of data collection itself, we focus on the period since the economic recovery began in $2001 .{ }^{7}$ We use monthly data to compensate for the short sample period, but there are no reliable real sector statistics available at a monthly or quarterly frequency. ${ }^{8}$ Our included variables are therefore limited to price data, monetary statistics, and international prices.

The lack of real sector statistics rules out numerous models that identify aggregate demand disturbances as a source of inflation. For example, the classic Blanchard and Quah (1989) structural VAR model containing inflation and the unemployment rate distinguishes between aggregate demand and supply disturbances through a restriction that rules out any long-run effect of aggregate demand disturbances on the unemployment rate. ${ }^{9}$ This type of model is based on a general neutrality hypothesis where in the long run aggregate demand disturbances do not affect real variables. For Sierra Leone, we cannot employ this approach because of a lack of reliable real sector data. It is also common to model inflation as a function of the output gap, but given that we cannot measure the output gap reliably, again this approach is not viable for Sierra Leone.

We do have enough data to model the effect of price shocks-e.g., pass-through of changes in international prices or changes in domestic supply conditions that trigger a price response-on inflation. Given their large run-up in recent years, international oil prices are an obvious candidate for inclusion. The exchange rate is another candidate, in particular for

\footnotetext{
${ }^{7}$ A civil war started in 1991 when the Revolutionary United Front embarked on its campaign against the government in the Eastern Province of Sierra Leone. By 1995 the war had spread across the whole country.

${ }^{8}$ Even annual real sector data are often unreliable in the immediate years following the end of civil war.

${ }^{9}$ The term “structural VAR” denotes a model with identifying restrictions, as explained below.
} 
modeling pass-through effects. This leaves supply shocks, especially harvest conditions, as a third source driving price changes. This type of shock could be proxied directly with food prices, which respond quickly to agricultural conditions, but this would be impractical: Food is by far the largest component in Sierra Leone's CPI basket, and including it directly in the model as an explanatory variable would effectively remove it from the inflation analysis. Because we do not have any direct measure for conditions that affect the harvest, we will instead interpret price shocks that are not explained by the other variables in the model as representing a harvest-type supply shock. We expect that the price effects of harvests should recede within a year-by the time the next harvest comes in-so they are more influential in the short run than over the medium term.

Our model captures two key monetary policy objectives for Sierra Leone: inflation and the exchange rate. In a typical Taylor-type reaction function, monetary policy is considered to respond to inflation (representing central bank targeting of inflation) as well as the output gap (representing central bank efforts to stabilize the real economy). Sierra Leone’s central bank seems to be committed to targeting a single-digit inflation rate, but stabilizing the real economy is probably a secondary objective because it is severely complicated by the lack of reliable real sector data. In an open economy the central bank may also have an exchange rate objective; in the case of Sierra Leone, there is some debate whether the central bank pursues an exchange rate target - the authors of this paper do not think so-but it is clear that the central bank is concerned with exchange rate volatility, particularly to the extent that its own foreign exchange interventions could lead to undesirable fluctuations.

One crucial variable is nevertheless missing: government financing requirements. Regarding monetary policy operations, our model assumes central bank control of reserve money, but in practice fiscal policy and administrative capacity constraints can interfere with targeting reserve money (see Text Box 1). Government financing requirements should therefore have been included in the model to capture the fiscal policy constraint on monetary policy, but there are no long-run monthly time series data. This poses a problem because it means the monetary policy reaction function in our model is incomplete, making it doubtful whether we can identify the monetary policy shock correctly, which is central to the VAR analysis below. 
The empirical results, however, display broadly plausible responses to the monetary policy shock, which suggests that this shortcoming is not fatal. 


\section{Text Box 1. Sierra Leone: Monetary and Fiscal Policy Coordination}

The Bank of Sierra Leone (BSL)'s monetary policy objective is to maintain a low level of inflation. To achieve its objective, the BSL targets reserve money growth. However, the conduct of monetary policy has been hampered by institutional weaknesses and fiscal needs. A critical institutional weakness has been, until recently, the lack of instruments to conduct open market operations; the central bank's capital position has been weakened by a large stock of noninterest, nonnegotiable government securities (with a zero face value), while its portfolio of treasury bills and treasury bearer bond was insufficient to conduct meaningful open market operations. Furthermore, the fiscal policy stance conflicted at times, with the BSL's reserve money target. The result was a mostly passive monetary policy stance that resulted in frequent overshoots of its intermediate monetary target, contributing to persistent high inflation in Sierra Leone (see figure below).

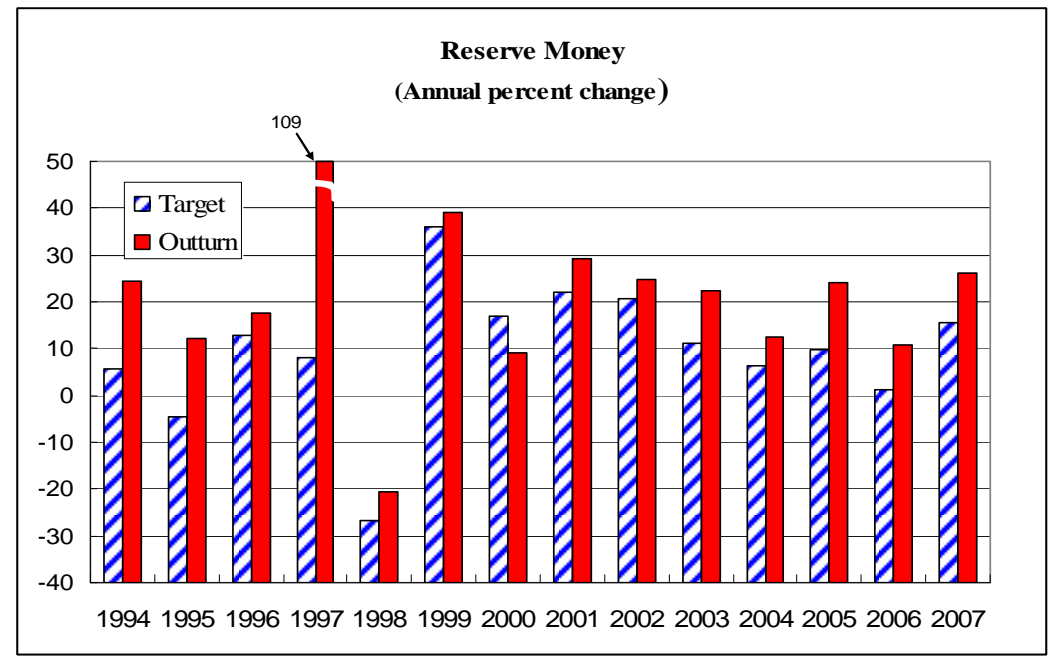

Fiscal expansion has complicated the conduct of monetary policy because deficit financing through foreign grants and borrowing from the central bank tends to increase the money supply in the absence of sterilization. An alternative to open market operations for sterilizing the increase in the money supply could have been the sales of foreign exchange. The BSL, however, was unwilling to do so, because (i) over many years its primary objective was building up a comfortable reserve cover, and (ii) there was concern that such sales could lead to undesirable exchange rate fluctuations.

In October 2006, the BSL and the Ministry of Finance signed a Memorandum of Understanding (MoU) setting amongst other things, a timetable for the conversion of part of the noninterestbearing, nonnegotiable government paper into treasury bills to (i) replenish the prescribed minimum paid up capital of the central bank; and (ii) provide the BSL with instruments to conduct open market operations. The BSL has favored a gradual approach in implementing the provisions of the MoU in order to avoid a significant and sudden upward pressure on nominal interest rates and thus on the government interest bill. 


\section{B. VAR Methodology}

In employing the VAR methodology for modeling inflation dynamics in Sierra Leone, our starting point is a reduced form model, which can be written in matrix form as:

$y_{t}=B_{0}^{*}+B_{1}^{*}(L) y_{t}+u_{t}$

where $y_{t}$ denotes a vector for the model variables, $u_{t}$ contains the reduced form residuals, $B_{0}^{*}$ represents the deterministic components of the reduced form model (e.g., constant and time trend), and $B_{1}^{*}(L)$ is a lag operator. Estimating the reduced form model is straightforward - it can be done using the conventional ordinary least square (OLS) estimator-but the estimated parameters have no economic interpretation. To overcome this drawback, we consider a structural model.

The structural model corresponding to the reduced form model (1) has the form

$$
\Gamma_{1} y_{t}=\Gamma_{0}+B(L) y_{t}+e_{t}
$$

with $\Gamma_{1}$ denoting the contemporaneous interactions between the variables, $\Gamma_{0}$ the structural deterministic components, $B(L)$ the lagged responses, and $e_{t}$ the structural residuals. Unlike the reduced form, the structural form includes contemporaneous interactions and represents a complete economic model. However, it cannot be estimated directly; it must be retrieved from the reduced form using identifying restrictions, because the estimated reduced form parameters are a combination of the structural parameters:

$$
B_{0}^{*}=\Gamma_{1}^{-1} \Gamma_{0}, B_{1}^{*}(L)=\Gamma_{1}^{-1} B(L), u_{t}=\Gamma_{1}^{-1} e_{t} .
$$


The VAR methodology differs from the traditional approach (as in Kallon, 1994) in the form of its identifying restrictions. To impose restrictions VAR models are reformulated into a moving average (MA) presentation. For the structural form, this yields:

$y_{t}=\left(\Gamma_{1}-B(L)\right)^{-1} \Gamma_{0}+\left(\Gamma_{1}-B(L)\right)^{-1} e_{t}=C(L) \Gamma_{0}+C(L) e_{t}$

where $C(L)=\left(\Gamma_{1}-B(L)\right)^{-1}$. To estimate the structural VAR, the reduced form needs to be transformed into its MA presentation as well:

$y_{t}=\left(I-B_{1}^{*}(L)\right)^{-1} B_{0}^{*}+\left(I-B_{1}^{*}(L)\right)^{-1} u_{t}=C^{*}(L) B_{0}^{*}+C(L) u_{t}$

with $C^{*}(L)=\left(I-B_{1}^{*}(L)\right)^{-1}$. Thus, the structural and reduced forms are linked by the following relations:

$C(L)=C^{*}(L) \Gamma_{1}^{-1}, C(L) \Gamma_{0}=C^{*}(L) \Gamma_{1}^{-1} \Gamma_{1} B_{0}^{*}$, and $e_{t}=\Gamma_{1} u_{t}$.

Using (6), the reduced form can be rewritten as

$y_{t}=C^{*}(L) \Gamma_{1}^{-1} \Gamma_{1} B+C^{*}(L) \Gamma_{1}^{-1} \Gamma_{1} u_{t}=C(L) \Gamma_{0}+C(L) e_{t}$.

Thus, once $\Gamma_{1}$ is identified, it is simple to compute the structural model from the reduced form. A standard identifying restriction for $\Gamma_{1}$ is that the structural shocks are orthogonal, 
which implies that, in the simplest bivariate case, the variance-covariance matrix for the structural shocks has the form ${ }^{10}$

$$
\Sigma_{e}=\left[\begin{array}{cc}
\sigma_{1}^{2} & 0 \\
0 & \sigma_{2}^{2}
\end{array}\right] .
$$

Restrictions on the short- or long-run responses of the model variables to structural shocks are another way to identify restrictions. Given the short sample period for the Sierra Leone model, we limit ourselves to short-run restrictions.

The structural residuals $e_{t}$, which are central to the VAR approach, are typically referred to as structural shocks. In contrast to the traditional approach-where residuals are considered to be simply noise- they are seen in the VAR approach as representing the exogenous primitive forces that buffet the economy and are responsible for its stochastic behavior. These primitive forces are assumed to be independent of each other, hence the orthogonality restriction. Their central role is encapsulated in the MA presentation which models variables as a function of the structural shocks in the model, plus the deterministic component: $y_{t}=C(L) \Gamma_{0}+C(L) e_{t}$. The empirical model can be assessed along three dimensions:

- Impulse response functions show how the model variables respond to individual structural shocks, e.g., an oil price shock.

- Variance decomposition shows the contribution of each structural shock to the forecast error variance of the variables in the model at different forecast horizonse.g., typically monetary policy shocks are imported for real exchange rate fluctuations in the short run but not in the long run.

\footnotetext{
${ }^{10}$ This implies one nonlinear restriction on the matrix $\Gamma_{1}$, because the variance-covariance matrix for the reduced form $\Sigma_{u}$ is linked to its structural counterpart by $\Sigma_{e}=\Gamma_{1} \Sigma_{u} \Gamma_{1}^{\prime}$.
} 
- $\quad$ Historical decompositions use the MA presentation and decompose the evolution of each model variable over time into portions representing the deterministic component and the individual structural shocks - e.g., one can compute the changes in the price level that are solely attributable to oil price shocks.

\section{Empirical Model for Sierra Leone}

Our VAR model consists of four variables (Figure 1):

- International oil prices, to capture the effect of recent price increases-pump prices are unregulated in Sierra Leone and should reflect international price movements; ${ }^{11}$

- $\quad$ CPI index for Sierra Leone as a price measure;

- $\quad$ Reserve money as a measure of monetary policy; ${ }^{12}$ and

- $\quad$ The nominal Leone/U.S. dollar exchange rate, as a measure of the exchange rate pass-through effect. ${ }^{13}$

\footnotetext{
${ }^{11}$ We used world average crude prices in US\$/ barrel from International Financial Statistics.

${ }^{12}$ We chose reserve money instead of broad money because the central bank has more control over it.

${ }^{13}$ We also considered the nominal effective exchange rate and found little qualitative difference; we preferred the bilateral exchange rate against the U.S. dollar, because use of the US dollar is common in Sierra Leone and policy discussions of exchange rate issues always focus on the bilateral Leone/US dollar exchange rate.
} 
Figure 1. Sierra Leone: CPI Index and Its Determinants, January 01-December 07 (Natural log)
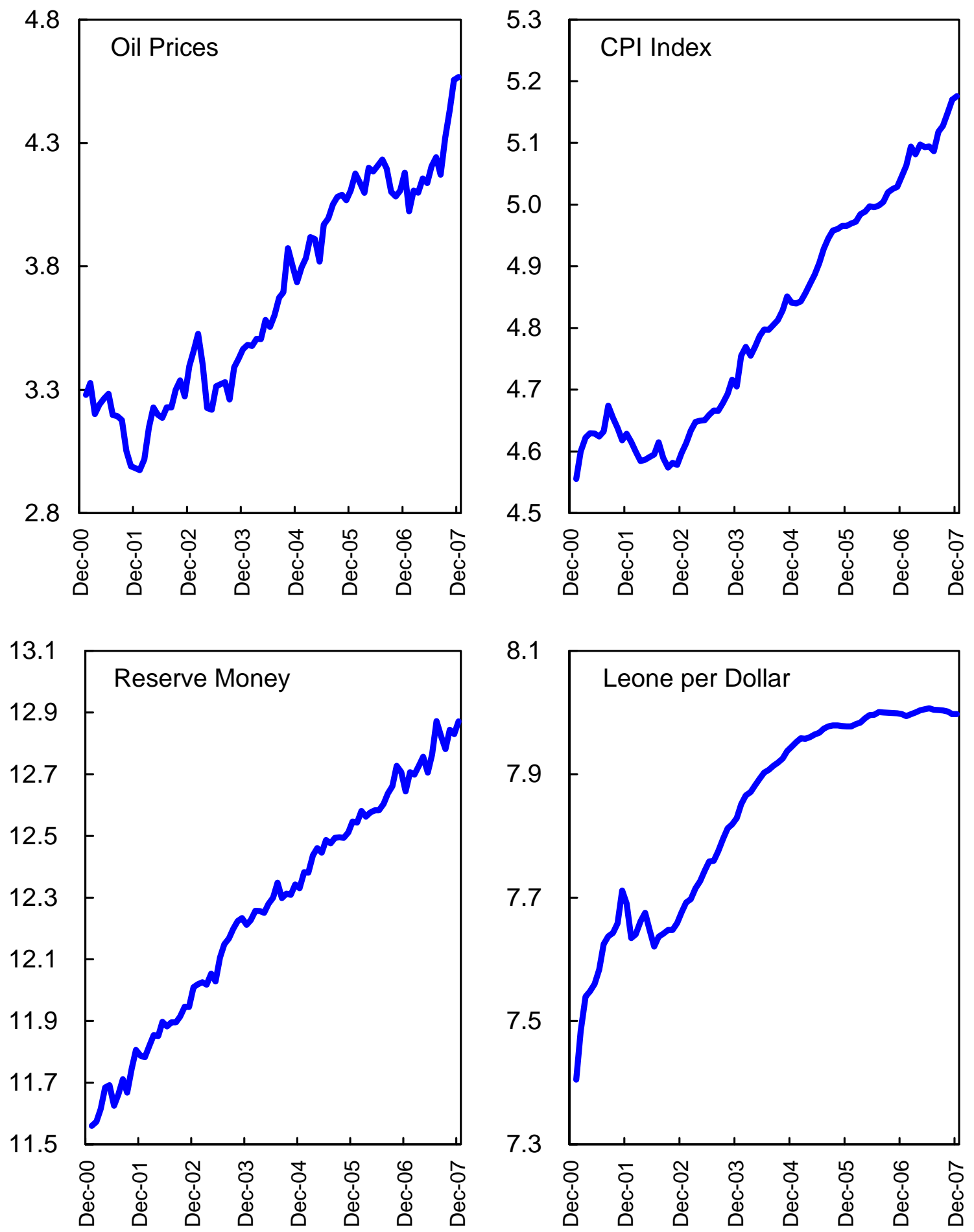

Sources: International Financial Statistics and the authors' calculations. 
We estimate our VAR model initially from 2001:1 through 2006:12 using monthly data and then extend the sample period to December 2007 to test the model's out-of-sample forecasting properties and generate a medium-term inflation forecast. All variables enter in natural logarithms and are seasonally adjusted. We do not attempt to explicitly model the long-run relationships using cointegration analysis because the sample period is too short for this to be meaningful. ${ }^{14}$ As for the deterministic components, we included both a constant and a trend; while a deterministic trend would not be necessary where there are stochastic trends, we include it nevertheless because the sample period may be too short to properly model stochastic trends, and because the deterministic trend is statistically significant in the model. Lag length was chosen to obtain a parsimonious model with reasonably well-behaved residuals, yielding a lag length of three. ${ }^{15}$

The VAR model broadly satisfies standard requirements. All roots of characteristic polynomials lie inside the unit circle, indicating that the model is stable (Appendix Figure A.1.). Multivariate Chow tests for break points suggest that the VAR model is stable throughout the sample period. Appendix Figure A.2. shows the p-value of the Chow tests where the null hypothesis is no structural breaks in the VAR model. The p-values are significantly higher than 5 percent, indicating the null hypothesis cannot be rejected. Lagrange Multiplier (LM) tests of serial correlations in the residuals raises some concerns for the first 3 lags, but higher lags show no sign of serial correlation (Appendix Table A.1.). In response, we decided to set the lag length equal to three, which improves also the normality property of residuals. The p-value of joint normality tests applied to the residuals is higher than 5 percent (Appendix Table A.2.), indicating that the residuals are normally distributed. Finally, we tested whether the residuals contain heteroskedasticity. We could not fully overcome this issue - test results of the null hypothesis of no heteroskedasticity show mixed

\footnotetext{
${ }^{14}$ The VAR model in level nevertheless, allows implicitly for cointegration relationships. Even without cointegration, it is not necessary for VAR analysis to difference variables because each equation in the model contains lags of the endogenous variable, which makes the model relatively robust against 'spurious regression' concerns.

${ }^{15}$ Standard information criteria suggest a lag length of one, but with only one lag the model displays signs of severe non-normality.
} 
results when individual components are tested, but the null of no heteroskedasticity is rejected when they are tested jointly (Appendix Table A.3.).

We use short-run restrictions to identify our structural model: ${ }^{16}$

- We restrict the oil price variable to respond contemporaneously only to its own shock; this restriction results from the fact that world oil prices are exogenous and should not respond to developments in Sierra Leone.

- $\quad$ Domestic prices can respond contemporaneously to the oil price shock but not to shocks from reserve money or the exchange rate; this restriction is consistent with likely delays in the transmission mechanism of monetary policy or exchange rate pass-through on prices, whereas oil price changes are likely to affect pump prices, and prices overall, immediately.

- $\quad$ Reserve money can respond contemporaneously to the oil and price shocks but not to exchange rate shocks; this restriction reflects the fact that to our knowledge the central bank has no explicit exchange rate target and is unlikely to respond instantaneously to its movements.

- $\quad$ The exchange rate can respond contemporaneously to all other variables.

We also experimented with numerous other restrictions, but the results turned out to be relatively robust. In sum, our model identifies four structural shocks—an oil price shock; a price shock representing conditions affecting the harvest; a monetary policy shock; and an exchange rate shock. In what follows we discuss the resulting impulse response functions, variance decomposition, and historical decomposition for Sierra Leone.

\footnotetext{
${ }^{16}$ We also impose the standard orthogonality restriction. The short-run restrictions are implemented using the Choleski decomposition.
} 


\section{Estimation Results}

\section{Impulse Reponses}

Impulse response functions show how the model variables respond to individual structural shocks: changes in oil prices, domestic prices, monetary policy, and the nominal exchange rate.

\section{Response to Oil Price Shock}

The first column in Figure 1 shows the impulse-response functions of the model variables to a one-standard-deviation oil price shock; the dashed lines indicate the 95 percent confidence interval. In addition to the four model variables, Figure 1 also shows the response of the real exchange rate and the annual inflation rate (computed as the year-over-year change in the $\mathrm{CPI})$, but without the confidence bands. All variables are in logarithms and the deviation from the baseline can be interpreted as percent deviation.

The oil price shock leads to a temporary rise in oil prices, increasing on impact by about 6 percent (Panel 1). Higher pump prices and second-round effect raise the overall price level, with prices increasing after about six months by about 1 percent and then declining slowly to their baseline level (Panel 2). Monetary policy responds by tightening the monetary policy stance, i.e., reserve money declines (Panel 3). Higher prices induce a nominal depreciation in the exchange rate (Panel 4), even though the exchange rate appreciates in real terms (Panel 5). The path for the annual inflation rate mirrors that of the price level, peaking after about six months and declining afterward - eventually becoming negative-as prices return to their baseline. In the long run all variables return to their baseline.

Whereas Figure 1 shows the effects of a temporary increase in oil prices, Figure 3A (Appendix) depicts the effects of a permanent increase in oil prices. ${ }^{17}$ In this case, the effect on the price level is permanent. This is consistent with monetary policy allowing first-round

\footnotetext{
${ }^{17}$ Figure $3 \mathrm{~A}$ is computed as the cumulative impulse response functions shown in Figure 1.
} 
effects to unfold-leading to the permanent increase in the price level—while preventing second-round effects like wage-price spirals that would raise the inflation rate permanently. This is in line with standard monetary policy practice.

The overall response is consistent with a cost-push shock. Pass-through leads to a general price increase that is dampened by tighter monetary policy and real exchange rate appreciation. The real exchange rate appreciation could be part of the monetary transmission mechanism or reflect market imperfections that prevent a full pass-through of higher prices

to the nominal exchange rate. It sets in immediately and is relatively large (about 0.5 percent) compared to the increase in overall prices. This suggests that real exchange rate responses have an important role in dampening the price increase.

\section{Response to Price Shock}

The price shock is another type of adverse supply shock. Whereas the oil price shock is due to a change in international prices, the price shock is meant to capture domestic supply disturbances like poor harvests that drive up domestic prices. The price shock leads to an immediate increase in the CPI by about 10 percent, which then recedes, becoming statistically insignificant about 10 months, in line with our expectations for a shock representing harvest conditions. After an initial accommodation, monetary policy begins to lean against this shock after about three months by reducing money supply below the baseline; in comparison to the oil-price shock response, the reduction in money supply is more persistent. The monetary tightening induces both a nominal and real appreciations. The latter sets in immediately, reaching about 1 percent. The general response is similar to that of the oil price shock, with the main difference being a more persistent monetary policy response.

\section{Response to Monetary Policy Shock}

The monetary policy shock leads to an initial increase in reserve money of about 2.5 percent, which quickly dissipates. The fact that this shock is short-lived is consistent with the notion that a monetary policy shock represents discretionary monetary policy actions that often arise 
because of policy errors that are quickly reversed; these errors, which can be the result of incomplete data at the time of decision making, are corrected once more information becomes available. 
Figure 2. Impulse Response Functions

Response to Oil Price Shock

Response of Oil

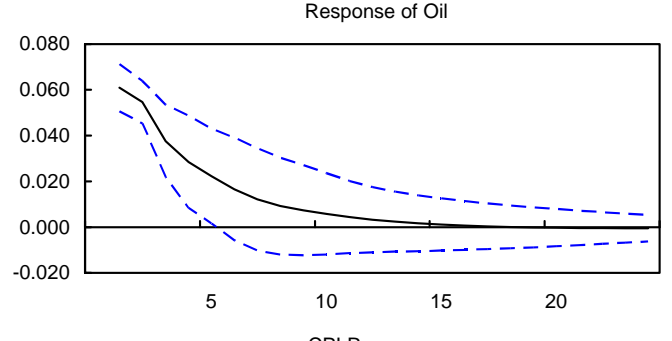

CPI Response

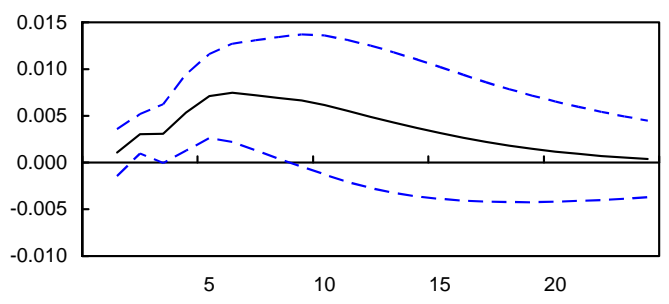

Response of Reserve Money

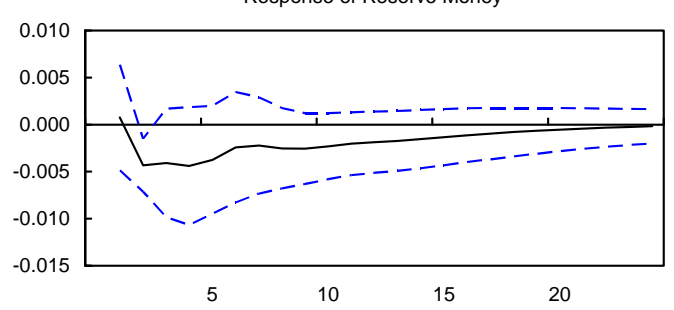

Exchange Rate (Le/US\$) Response

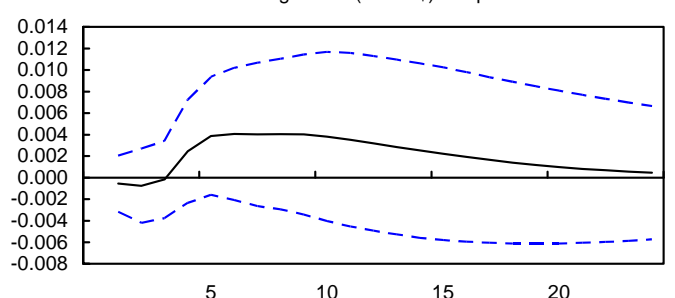

Real Exchange Rate Response
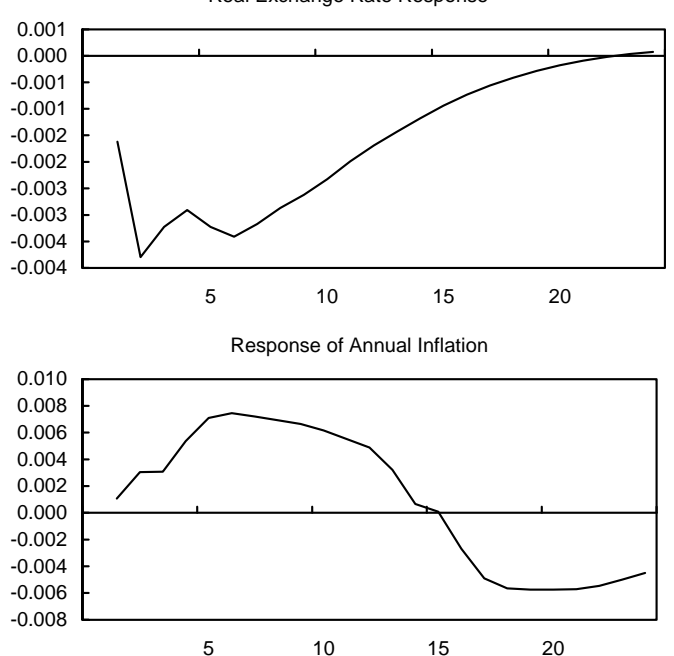

Response to Price Shock

Response of Oil
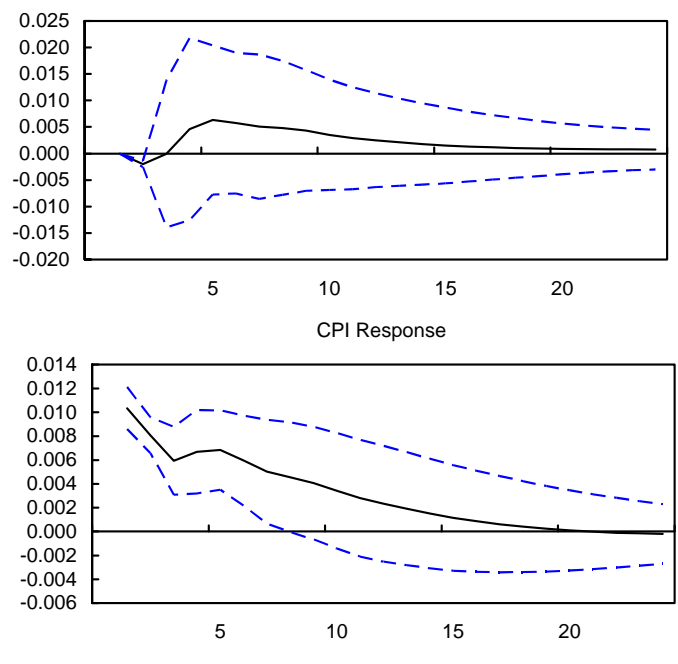

Response of Reserve Money

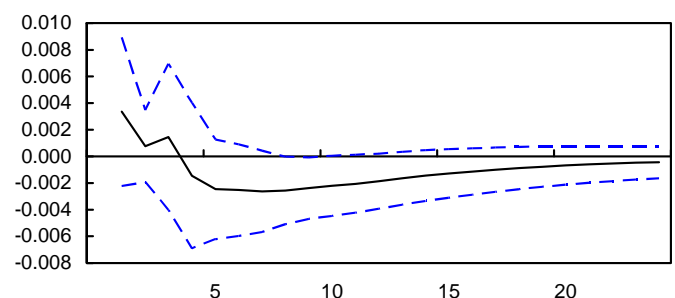

Exchange Rate (Le/US\$) Response

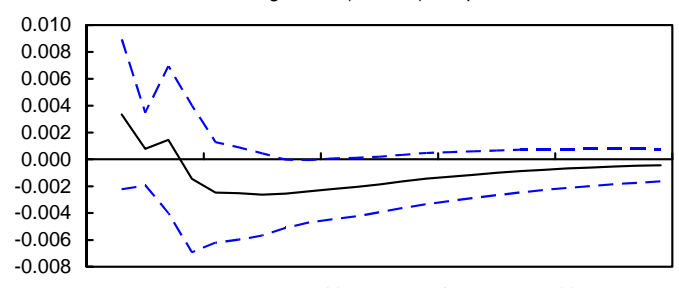

$\begin{array}{llll}5 & 10 & 15 & 20\end{array}$

Real Exchange Rate Response
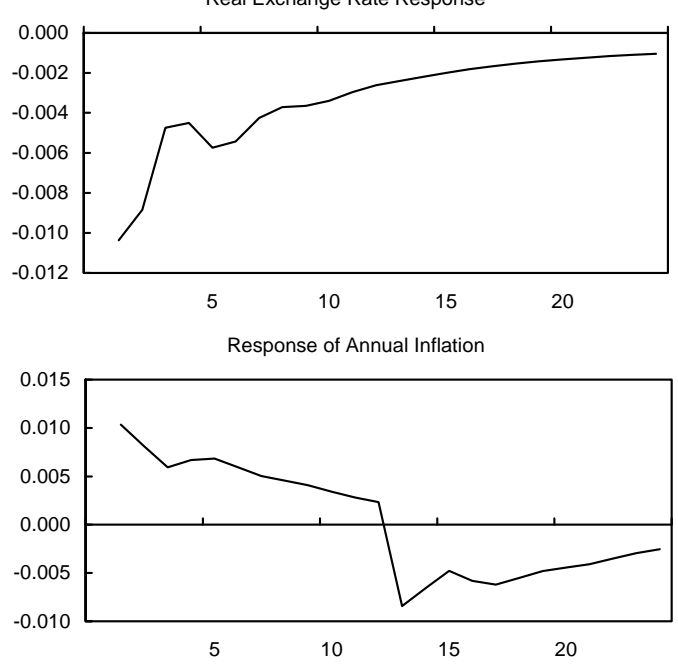
Figure 2. Impulse Response Functions (continued)

Response to Monetary Policy Shock

Response of Oil
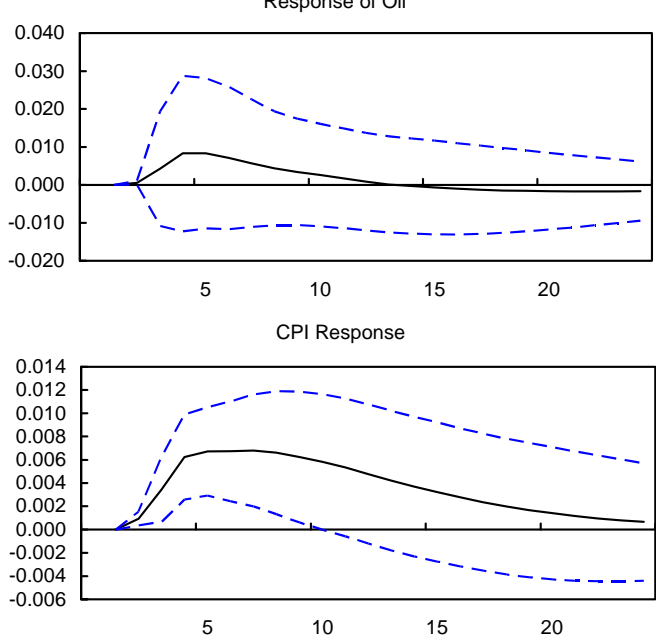

Response of Reserve Money

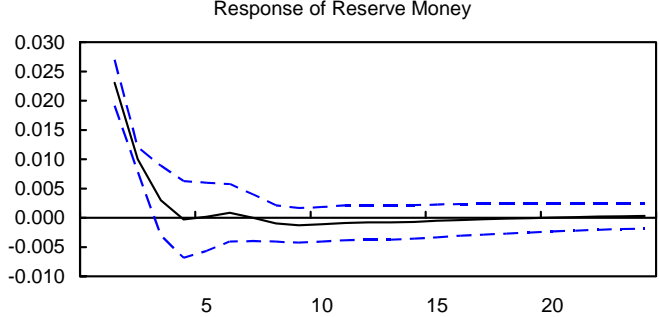

Exchange Rate (Le/US\$) Response

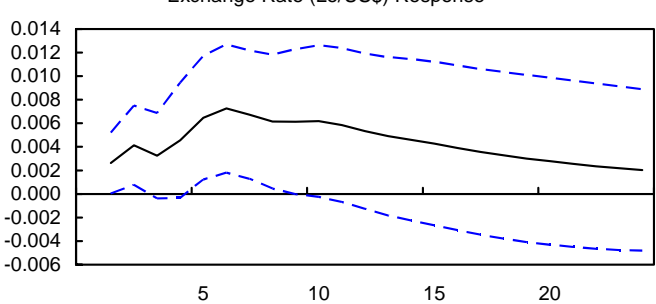

Real Exchange Rate Response
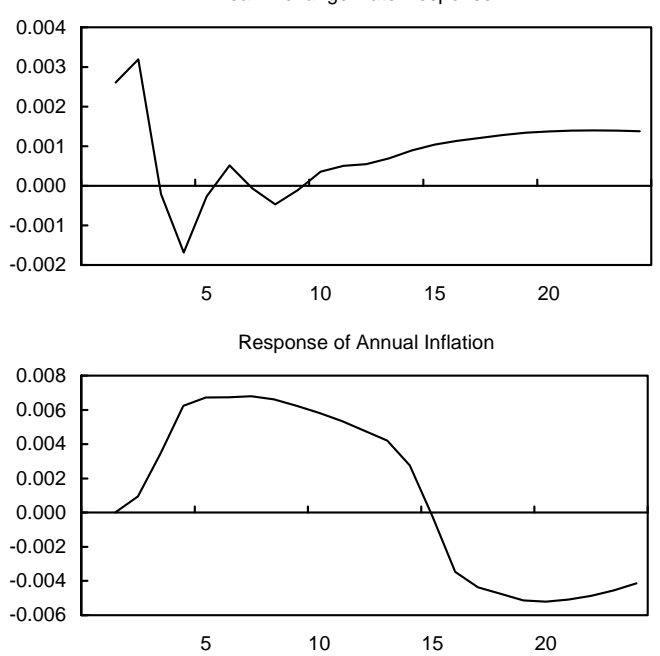

Response to Exchange Rate Shock
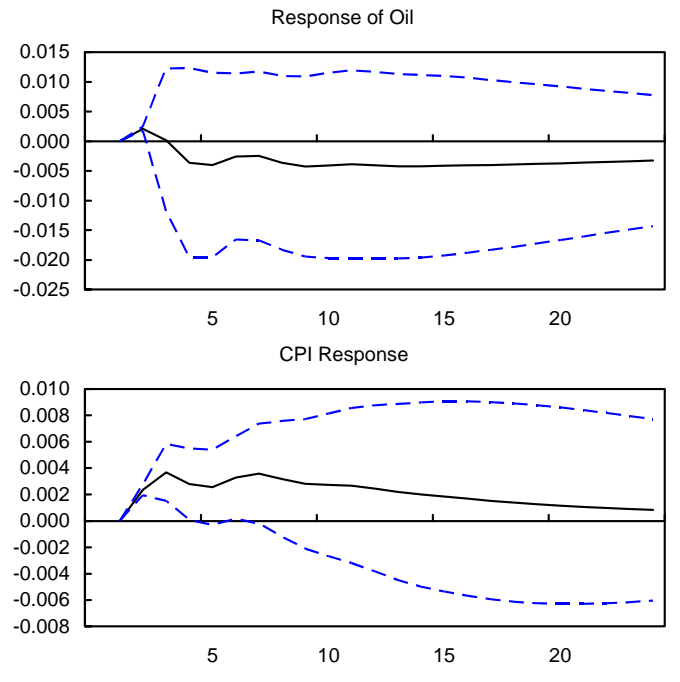

Response of Reserve Money

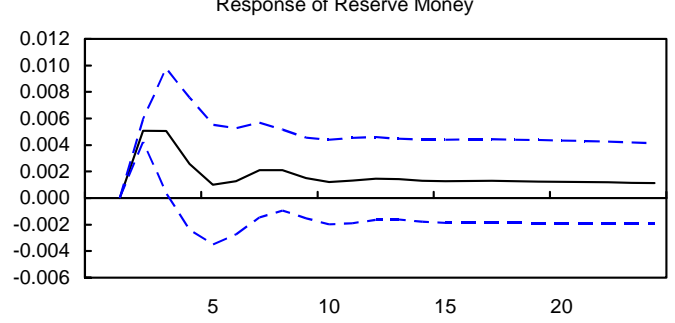

Exchange Rate (Le/US\$) Response

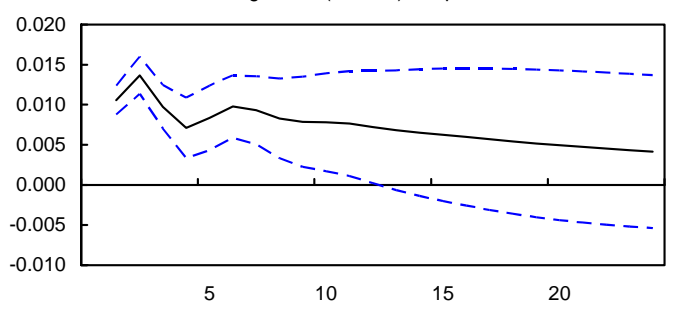

Real Exchange Rate Response
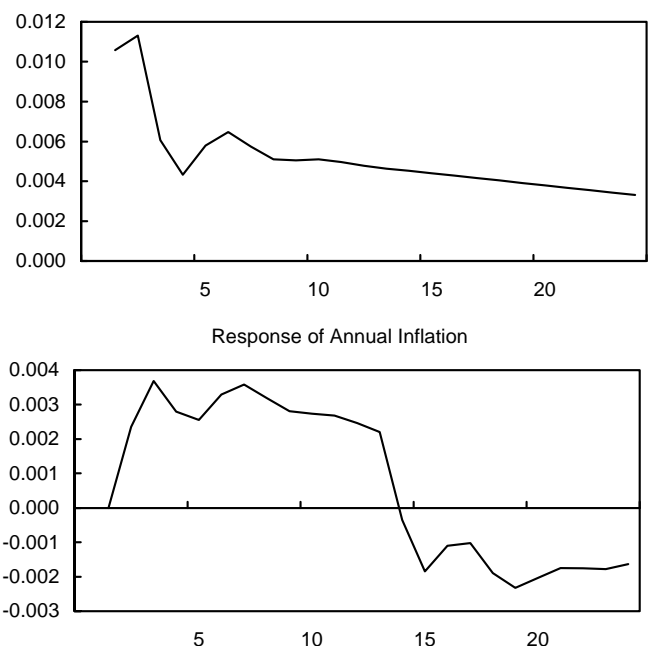
The expansion in reserve money leads to an increase in the price level; it takes about six months for the price effect to take full effect, with prices having increased by about 0.5 percent at their peak. The nominal exchange rate depreciates approximately in line with the increase in prices, leaving the real exchange rate broadly unchanged except for an initial real depreciation.

The overall response is consistent with theory: an expansionary monetary policy raises prices with some delay, induces nominal exchange rate depreciation, and is neutral with respect to real variables in the long term.

\section{Response to Exchange Rate Shock}

The exchange rate shock leads to a depreciation of the Leone/US dollar exchange rate of about 1 percent on impact. The nominal depreciation is relatively persistent, returning only slowly to its baseline. After a delay of about three months, pass-through effects lead to prices that are higher by about 0.4 percent; this effect is also persistent. Higher prices limit real exchange rate depreciation. Monetary policy accommodates this shock by expanding money supply; this is probably a major reason for the persistence of this shock.

The monetary policy response suggests that the central bank is not actively pursuing an exchange rate target, at least not in the short run. Otherwise, the central bank would probably sell foreign exchange in response to a Leone depreciation, which would induce a monetary contraction. ${ }^{18}$ Since the central bank is a relatively minor actor in the foreign exchange market, which is dominated by transactions related to diamond mining, this is likely a rational strategy.

\footnotetext{
${ }^{18}$ Assuming the central bank would not sterilize the impact of its sale of foreign exchange on money supply.
} 


\section{Text Box 2 Sierra Leone: Pass-through of Oil Prices and Exchange Rates}

In traditional regression analysis, pass through of changes in oil prices or the exchange rate to domestic inflation is determined by estimating the oil and exchange rate coefficients in a regression equation that determines inflation as a function of these and other variables. These coefficients can be interpreted as giving the inflation response to a 1 percent change in oil prices or exchange rates, i.e., these are the pass-through coefficients. In VAR analysis, there is no single coefficient but the impulse response functions that capture pass through of oil price or exchange rate shocks to inflation. However, to simplify the pass-through analysis, it is useful to transform the impulse response functions in such a way that they show the response of domestic prices (i.e., the CPI level) and annual inflation to a 1 percent permanent increase in the level of oil prices and the exchange rate respectively.

For oil price pass through, the graph below shows the response to a cumulative oil price shock that has been rescaled to yield a 1 percent permanent increase in oil prices (see Figure A.3. in the appendix for a complete set of impulse response functions). This leads to an increase in the CPI level of about 0.3 percent and a temporary increase in inflation of the same magnitude.

For the exchange rate pass through, we constructed a linear combination of exchange rate shocks that yields approximately a 1 percent permanent depreciation. The CPI and inflation response is also about 0.3 percent.
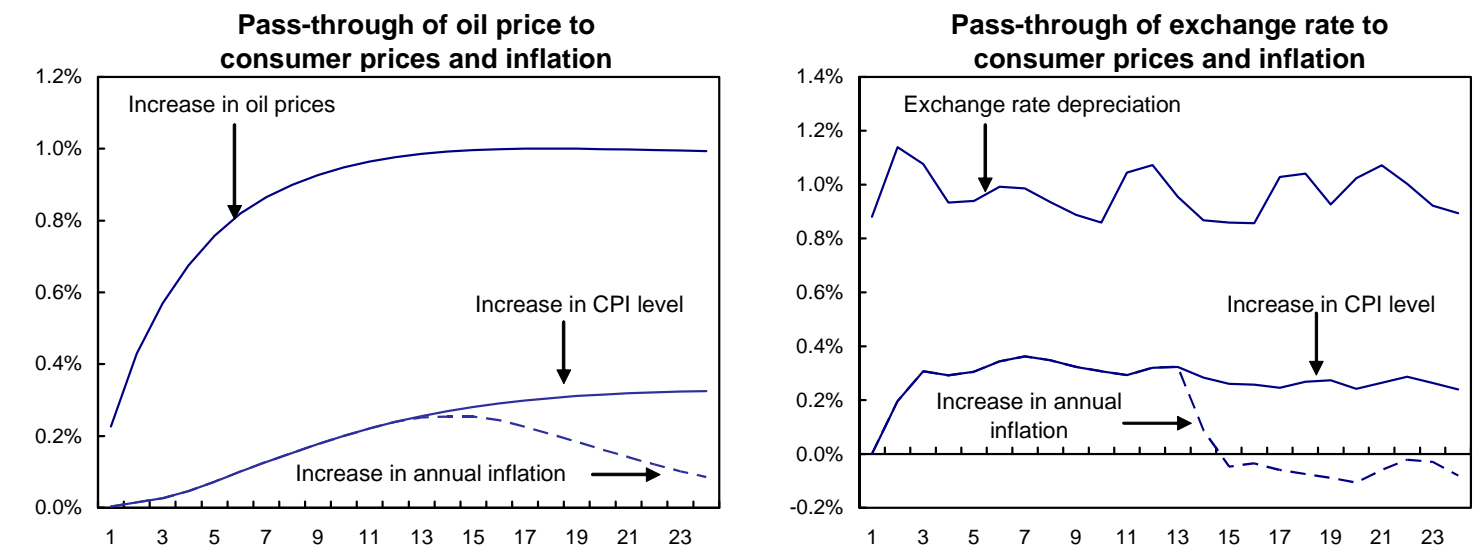


\section{Variance Decomposition}

The variance decomposition shows the contribution of each structural shock to the forecast error variance of the variables in the model at different forecast horizons. Key results are:

- $\quad$ Price shocks - which we interpret mostly as food-supply shocks due to harvest conditions — dominate price variations in the short run, i.e., over six months, but recede in importance as new harvests come in.

- $\quad$ Monetary policy shocks have a negligible effect on the real exchange rate, the only real variable in our model, confirming the neutrality hypothesis. ${ }^{19}$

- $\quad$ Variance in prices and inflation is due to multiple shocks: in the short run, the variation in prices is caused mostly by price shocks; in the longer term it depends in about equal measure on oil, price, and monetary policy shocks. ${ }^{20}$ The variance decomposition for inflation is similar but gives more weight to price shocks.

- $\quad$ Exchange rate variations are mostly due to exchange rate shocks and to a lesser extent monetary policy shocks. The prominence of exchange rate shocks may be due to factors not included in the model, in particular the supply of foreign exchange because of diamond exports.

- Variations in the real exchange rate depend significantly on price shocks. Technically, this is because price shocks have large effects on the price level, leading to a real appreciation. However, the role of monetary policy is significant because a tightening of monetary policy induces a nominal appreciation that reinforces the real appreciation. Otherwise, higher prices would lead to a nominal depreciation that leaves the real exchange rate relatively unchanged, as is the case for the monetary policy shock.

\footnotetext{
${ }^{19}$ Monetary policy shocks dominate the variation in reserve money, which would suggest that most monetary policy actions are discretionary; however, this likely reflects in part the incomplete specification of the monetary policy reaction function because of lack of data on government financing requirements.

${ }^{20}$ Note that the response of most variable dies out after about 12 to 18 months; the limited variation at longer horizons reduces the economic significance of the variance decompositions for these horizons.
} 
Table 1. Sierra Leone: Results for the Variance Decomposition

\begin{tabular}{|c|c|c|c|c|}
\hline \multirow[b]{2}{*}{ Variation in: } & \multicolumn{4}{|c|}{ Contribution of: } \\
\hline & $\begin{array}{l}\text { Oil Price } \\
\text { Shock }\end{array}$ & Price Shock & $\begin{array}{c}\text { Monetary } \\
\text { Policy Shock }\end{array}$ & $\begin{array}{c}\text { Exchange Rate } \\
\text { Shock }\end{array}$ \\
\hline \multicolumn{5}{|l|}{ Price level } \\
\hline 1-month horizon & 1.0 & 99.0 & 0.0 & 0.0 \\
\hline 6-month horizon & 22.9 & 49.5 & 21.1 & 6.5 \\
\hline 12-month horizon & 30.9 & 33.3 & 28.2 & 7.6 \\
\hline 18-month horizon & 31.8 & 30.5 & 29.5 & 8.2 \\
\hline 24-month horizon & 31.7 & 30.1 & 29.7 & 8.5 \\
\hline \multicolumn{5}{|l|}{ Inflation } \\
\hline 1-month horizon & 1.0 & 99.0 & 0.0 & 0.0 \\
\hline 6-month horizon & 22.9 & 49.5 & 21.1 & 6.5 \\
\hline 12-month horizon & 30.9 & 33.3 & 28.2 & 7.6 \\
\hline 18-month horizon & 27.8 & 39.6 & 26.0 & 6.6 \\
\hline 24-month horizon & 30.5 & 35.8 & 27.5 & 6.3 \\
\hline \multicolumn{5}{|l|}{ Reserve money } \\
\hline 1-month horizon & 0.1 & 2.0 & 97.8 & 0.0 \\
\hline 6-month horizon & 9.3 & 3.5 & 79.6 & 7.5 \\
\hline 12-month horizon & 11.9 & 6.8 & 72.7 & 8.7 \\
\hline 18-month horizon & 12.6 & 7.6 & 70.4 & 9.5 \\
\hline 24-month horizon & 12.5 & 7.7 & 69.5 & 10.3 \\
\hline
\end{tabular}


Table 1. Sierra Leone: Results for the Variance Decomposition (concluded)

Contribution of:

\begin{tabular}{lcccc}
\multicolumn{1}{c}{ Variation in: } & $\begin{array}{c}\text { Oil Price } \\
\text { Shock }\end{array}$ & Price Shock & $\begin{array}{c}\text { Monetary Policy } \\
\text { Shock }\end{array}$ & $\begin{array}{c}\text { Exchange Rate } \\
\text { Shock }\end{array}$ \\
\hline Exchange rate & 0.3 & 0.0 & 5.7 & 94.0 \\
1-month horizon & 4.8 & 1.0 & 18.6 & 75.6 \\
6-month horizon & 8.3 & 0.7 & 24.7 & 66.4 \\
12-month horizon & 8.2 & 0.8 & 25.4 & 65.7 \\
18-month horizon & 7.6 & 1.2 & 25.0 & 66.2 \\
24-month horizon & & & & 48.9 \\
Real exchange rate & 1.1 & 47.0 & 3.0 & 50.1 \\
1-month horizon & 7.8 & 39.3 & 2.7 & 52.4 \\
6-month horizon & 9.5 & 36.0 & 2.1 & 55.5 \\
12-month horizon & 8.7 & 33.4 & 3.1 & 57.4 \\
18-month horizon & 8.0 & 31.5 & & \\
24-month horizon & & & & \\
\hline
\end{tabular}

\section{ANALYZing CAUSES OF InFLATION AND ForECASTING INFLATION}

\section{A. Analyzing the Decline in Inflation in 2006}

The annual inflation rate declines from about 13 percent in early 2006 to about 6 percent in summer 2006. To assess the causes for this decline, we employ the historical decomposition technique which allows us to decompose the evolution of each model variable over time into categories representing the deterministic component and the individual structural shock. The historical decomposition, which is based on the MA presentation of the model, $y_{t}=C(L) \Gamma_{0}+C(L) e_{t}$, decomposes each variable into a deterministic component encapsulating the impact of the constant and trend, $C(L) \Gamma_{0}$, and a stochastic component that 
models the role of the structural shocks. These are shown in Figure 2: Panel 1 displays the path for the annual inflation series for Sierra Leone together with the deterministic component; Panel 2 depicts the stochastic component, which corresponds to the difference between the annual inflation series and the deterministic component.

Figure 3. Historical Decomposition of Inflation in Sierra Leone , 2002 - 06
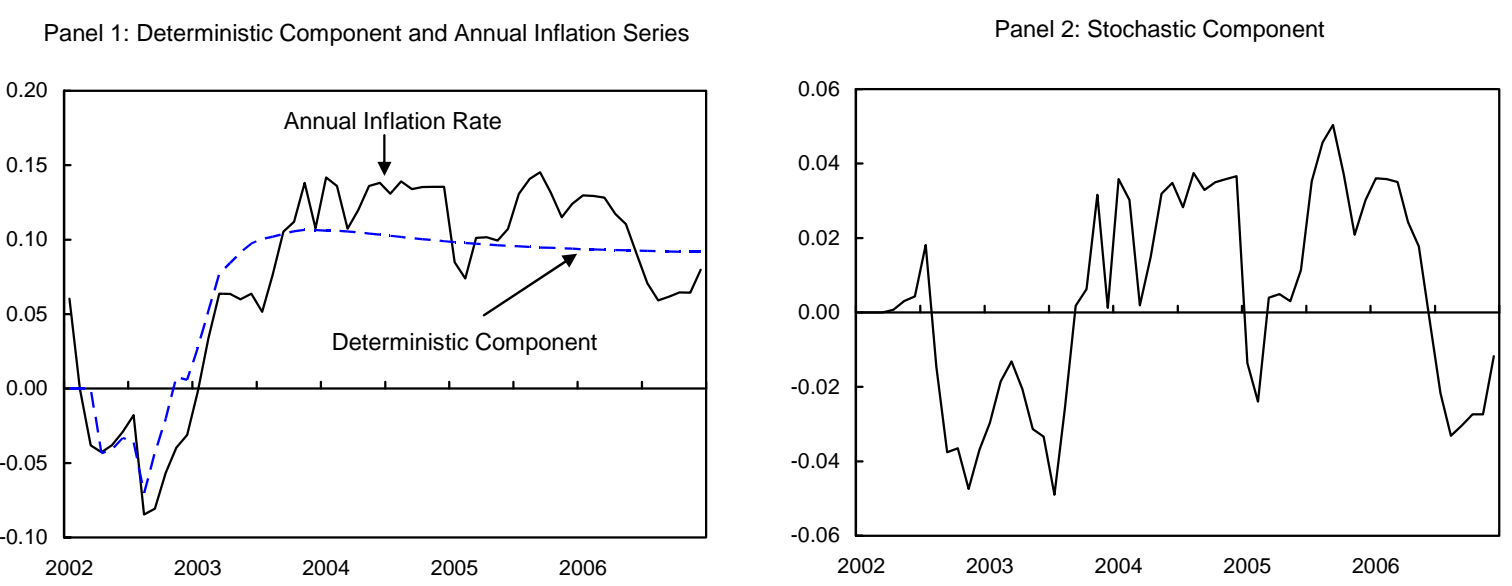

The deterministic component can be interpreted as an estimate of underlying inflation in the absence of any shocks. For Sierra Leone, underlying inflation measured this way was approximately 9 percent in 2006. The stochastic component accounts for variations in inflation around this trend. Of particular interest is the drop in inflation from 13 percent in March 2006 to 6 percent in August 2006. A further decomposition of the stochastic component, shown in Figure 3, identifies which shocks in particular were responsible for the decline in inflation: ${ }^{21}$

- $\quad$ Volatile oil prices were a key factor for inflation variation in Sierra Leone. The strong increase in oil prices between 2004 and summer 2006 (Figure 1) has raised consumer price inflation significantly (Figure 3, first panel, dotted line). Similarly, a plunge in oil prices in the second half of 2006 curtailed domestic inflation. However, another

\footnotetext{
${ }^{21}$ To obtain a better interpretation of the structural shocks, we found it useful to compute the historical decomposition for all variables in the system. These results are available upon request. Historical decomposition for oil prices shows, for example, that the model attributes the sharp drop in oil prices in the second half of 2006 to oil price shocks, and the role of the deterministic component of oil or other shocks in the model is minimal.
} 
factor is also at work: the peak effect of oil price shocks on domestic inflation occurs in mid-2005, despite the fact that oil prices increased for another year. The reason is that even permanent oil price increases have only a transitory effect on domestic inflation rate. ${ }^{22}$ This transitory effect implies that inflation initially increases in response to a permanent oil price increase, but later falls as the domestic price level stabilizes at its higher level. After mid-2005, the latter effect begins to dominate, which accounts for the reduction in inflation shown in the historical decomposition.

- $\quad$ Monetary policy shocks (i.e., discretionary monetary policy actions) are another factor for the drop in inflation in the second half of 2006. Inflation rose as monetary policy turned expansionary in early 2006 but later declined as it tightened. Here, the historical decomposition of reserve money shows that expansionary monetary policy in late-2005/early-2006 was due, not to high growth of reserve money, but to the fact that the central bank did not limit growth of reserve money in response to high oil prices sufficiently. ${ }^{23}$

- $\quad$ Price and exchange rate shocks, in contrast, did not have much influence on the drop in inflation in the second half of 2006.

\footnotetext{
${ }^{22}$ Figure A.3 in the Appendix depicts the response of the variables in our model to a permanent oil price shock: a permanent increase in oil prices raises the domestic price level permanently, whereas inflation, after an initial increase, returns to its baseline in the long run.

${ }^{23}$ More precisely, the central bank deviated from its monetary function by expanding reserve money along its trend path even though high oil prices would have called for a reduction - this deviation from the monetary reaction function is captured by the model as an expansionary monetary policy shock.
} 
Figure 4. Contribution of the Individual Structural Shocks

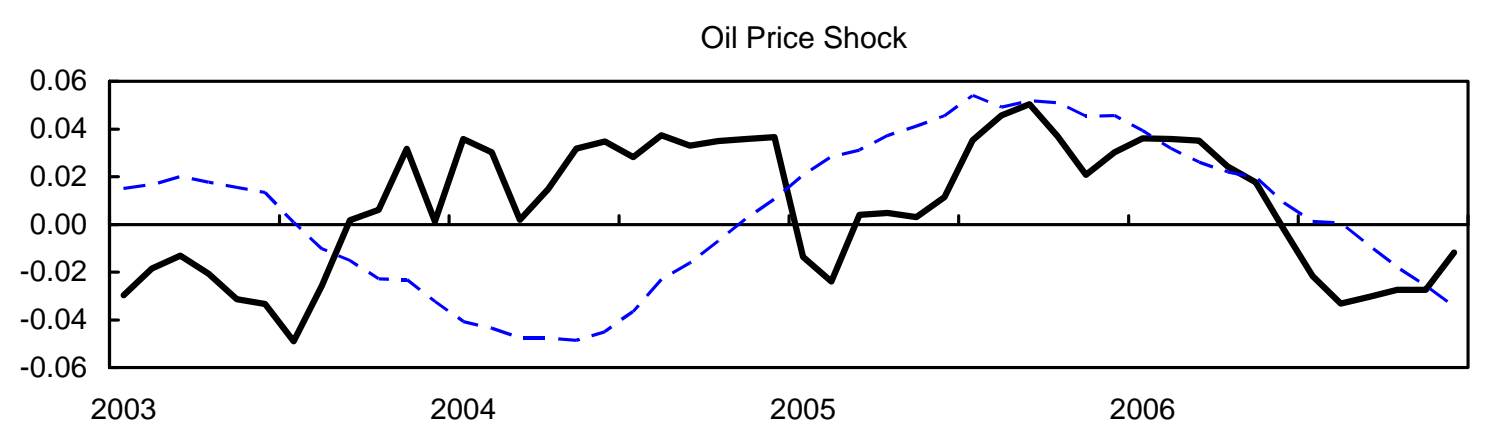

Price Shock

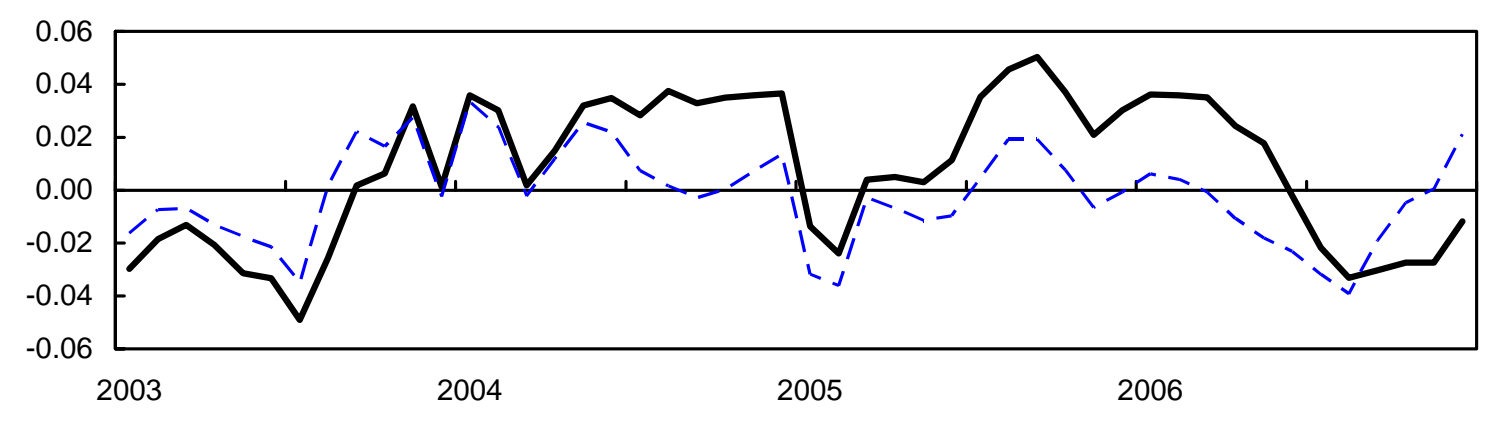

Monetary Policy Shock

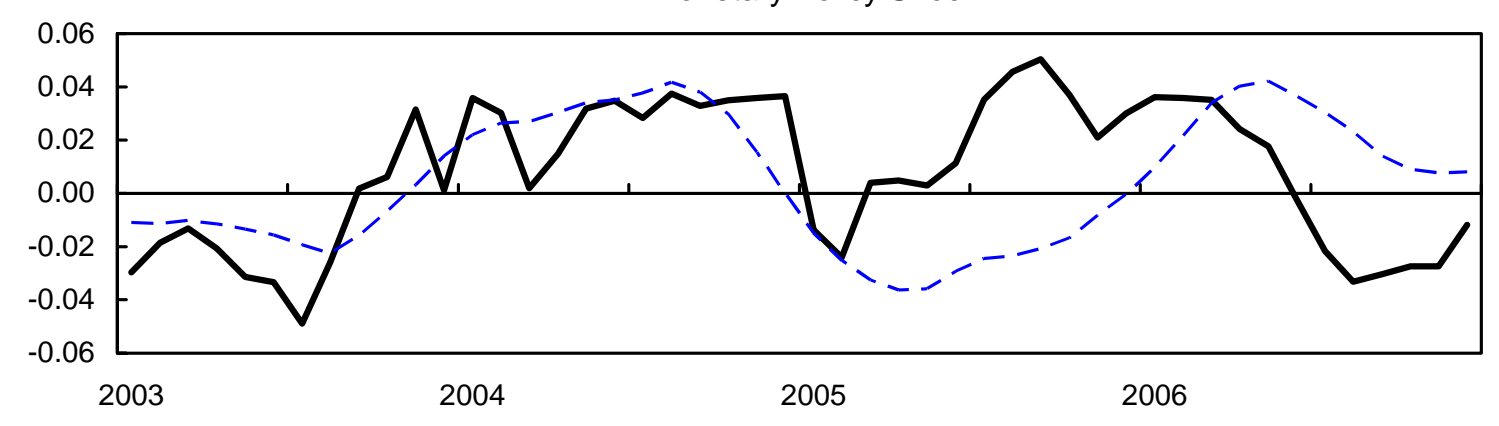

Exchange Rate Shock

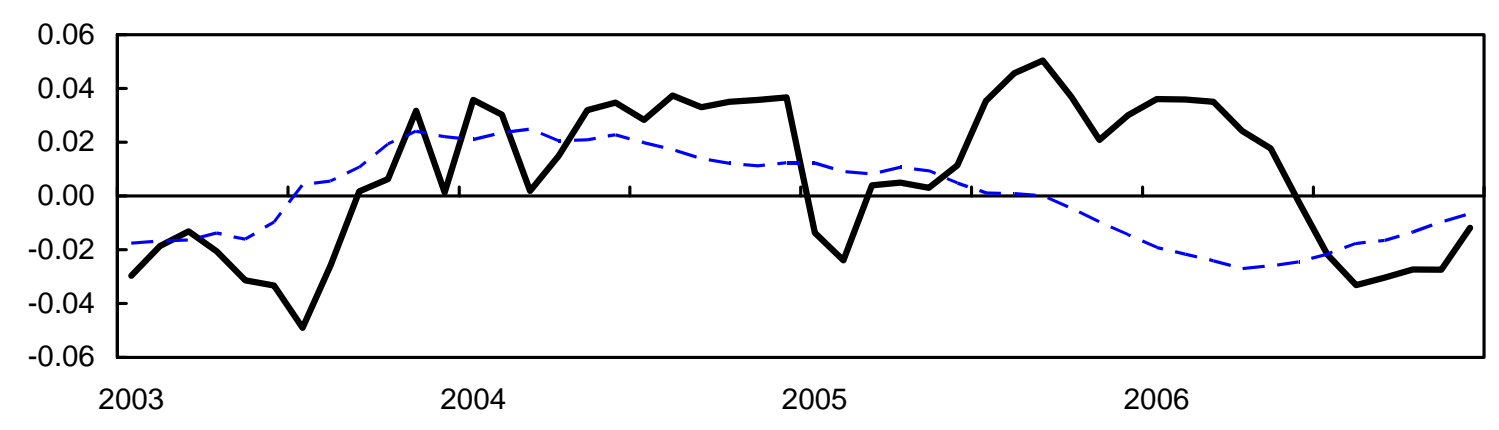




\section{B. Forecasting Inflation for $\mathbf{2 0 0 7}$}

Using the VAR model estimated up to end-2006 to generate an out-of-sample forecast yields a substantial underestimation of actual inflation in 2007. The inflation forecast of our end2006 model shows inflation increasing from its low levels in 2006 to about 9 percent (the level given by the deterministic component) by early 2008, whereas in reality inflation had already bounced back above 10 percent in early 2007 and reached 13 percent at the end of the year (Figure 4). A much more accurate forecast is obtained through an in-sample forecast that

Figure 5. Out-of-Sample Inflation Forecast (model estimated until end-2006)

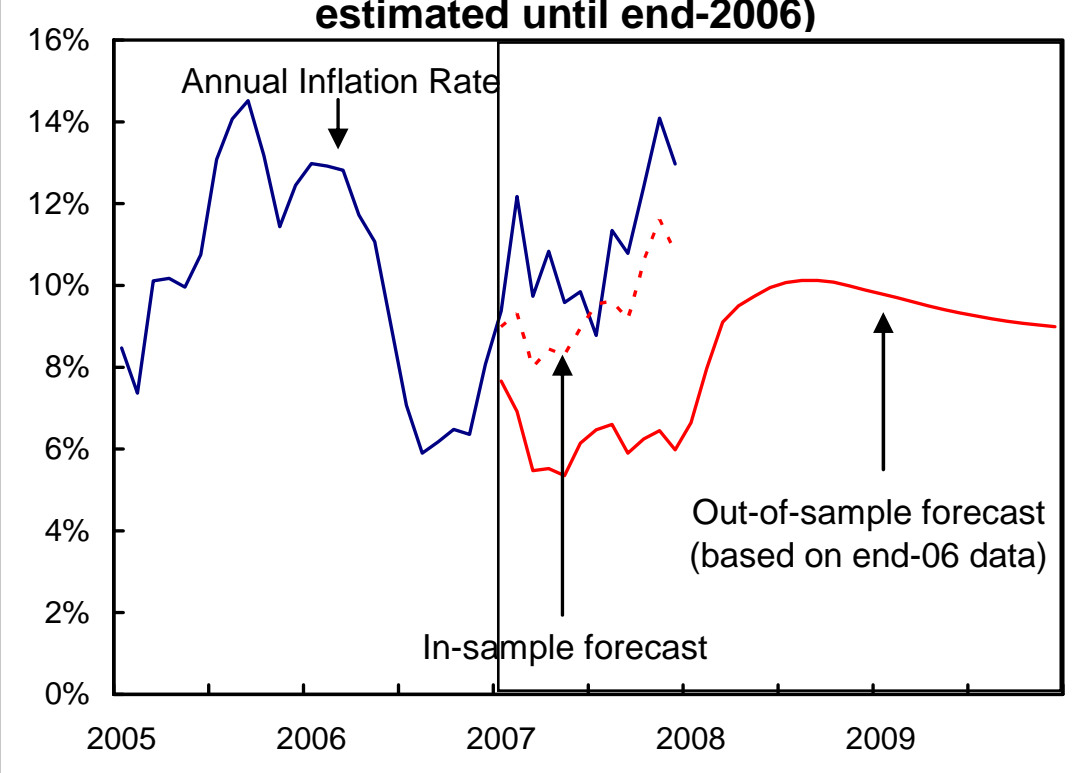

uses the price and inflation equations in our VAR and actual values for oil prices, money, and the exchange rate; this suggests that the bulk of the initial forecast error stems from unexpected developments in the latter three variables.

To pinpoint the sources of the forecast error more exactly, we re-estimate the model for 2007 and compute the corresponding historical decomposition. ${ }^{24}$ This shows that adverse price shocks (possibly related to poor harvest conditions) drove up inflation in 2007, which more than offset relatively tight monetary conditions and the dampening effect of (initially)

\footnotetext{
${ }^{24}$ Detailed results are available upon request.
} 
favorable oil price developments. ${ }^{25}$ As a result, the stochastic component swings from around -5 percent in the second half of 2006 to +1 percent in the final months of 2007 (Figure 5).

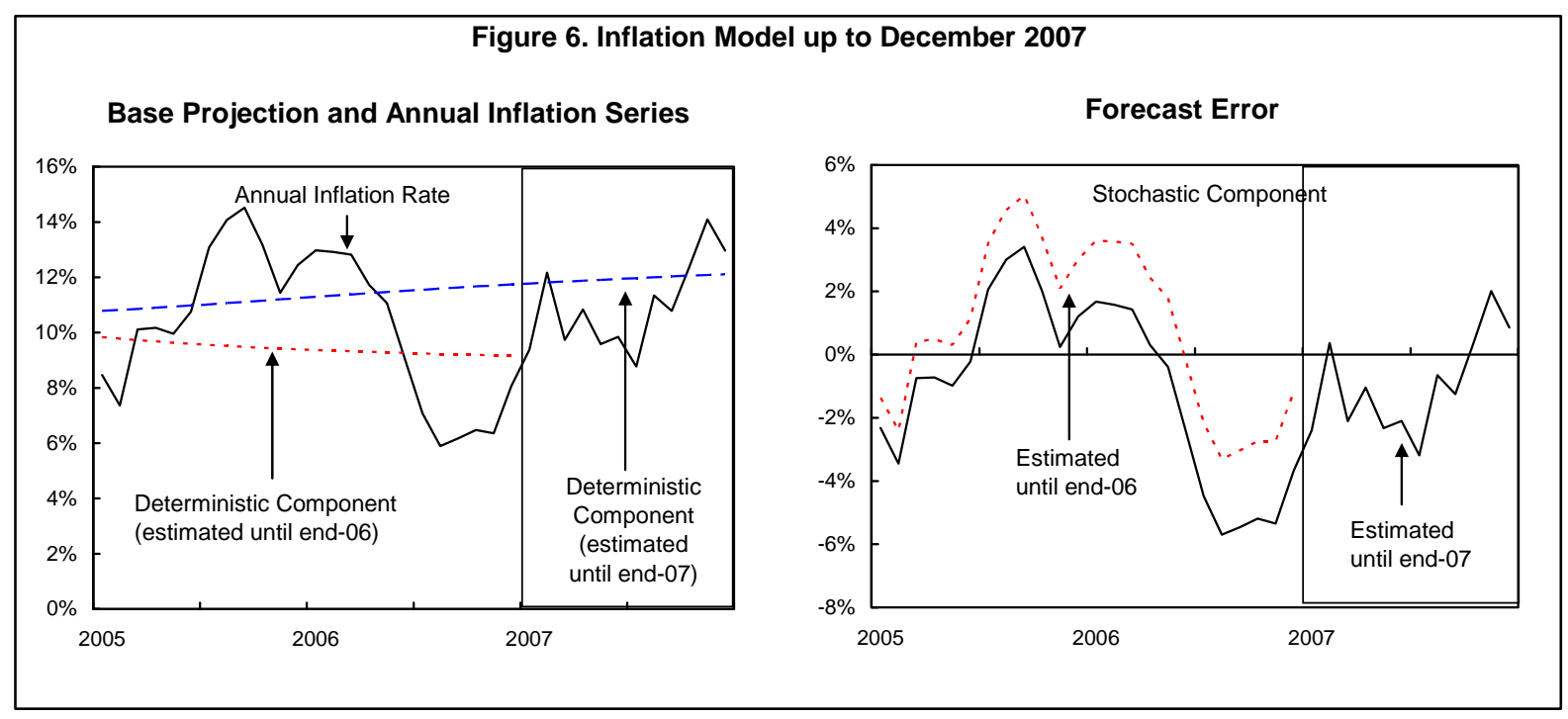

The increase in actual inflation in 2007 leads to a sizeable upward adjustment in the deterministic component: whereas previously it had been estimated to decline slightly, the revised estimate shows a small upward tendency in order to account for high inflation in 2007. Cumulatively, this leads to an upward revision in the deterministic component of $2 \frac{1}{2}$ percentage points at end-2006. While the profile of the stochastic component remains unchanged, the shift in the deterministic component implies a reduction in its size, i.e., it shifts downwards.

Overall, the under-prediction of inflation in 2007 reflects partly the occurrence of new shocks — which cannot be predicted by this (or any other) model—and partly a revision of the deterministic component, i.e., the model's estimate for underlying inflation. The latter raises some robustness concerns, meaning historical estimates are to some extent subject to change once new data becomes available. Nevertheless, the data revisions seem to affect mostly the level and much less the profile of either the stochastic or deterministic components, leaving the conclusions for the sources of inflation intact.

\footnotetext{
${ }^{25}$ Oil prices continue to decline in early 2007; together with the previous decline in 2006 this led to a reduction in inflation in the first half of 2007. In the second half, this effect receded as oil prices increased again.
} 


\section{Forecasting Medium-term Inflation}

In a final step, we use our VAR model (estimated until end-2007) to forecast inflation for the period 2008-10. The model predicts a sharp increase in inflation in 2008, which is likely driven by the large increase in oil prices in late 2007 (Figure 6). In the final quarter of 2007, oil prices increased by about 20 percent relative to the level in the third quarter (almost 50 percent year-over-year); given the pass-through estimate of 0.3 to domestic inflation discussed in

Text Box 2, this would account for the bulk of the predicted inflation spike in 2008. By

Figure 7: Out-of-Sample Inflation Forecast (model estimated until end-2007)

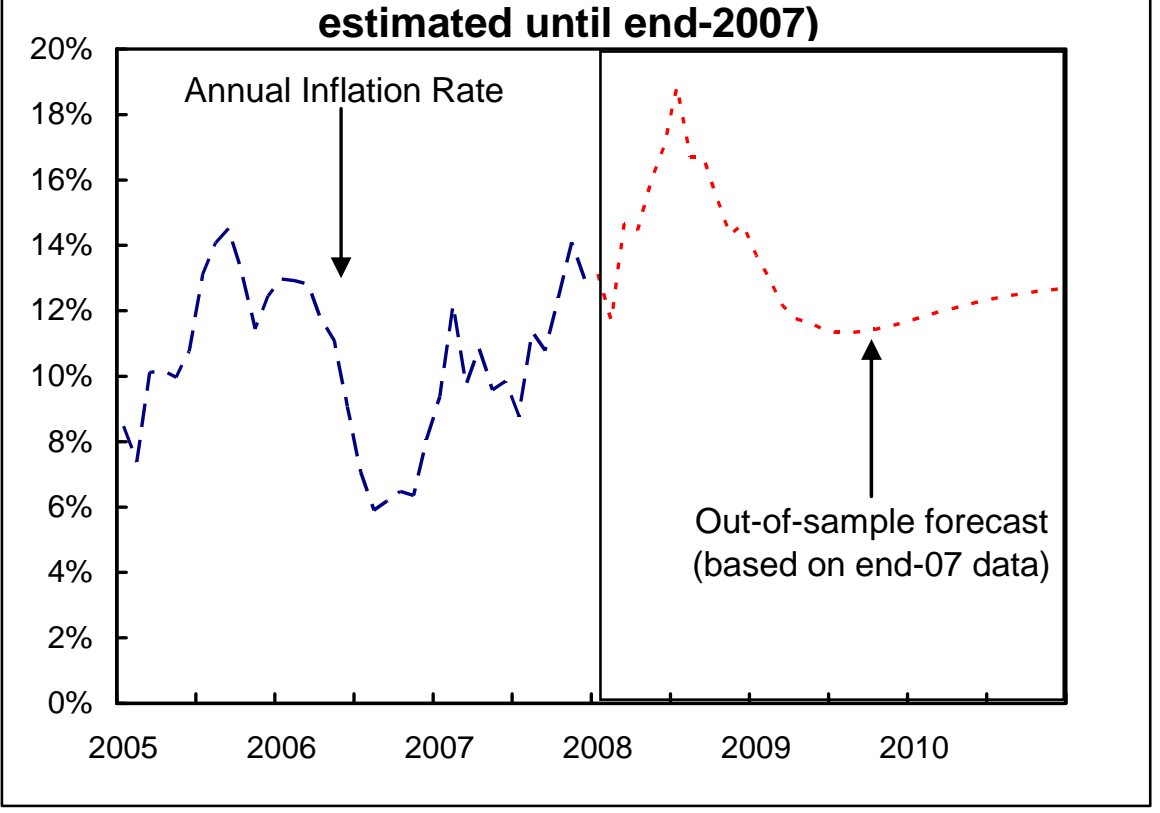

June 2008, inflation in Sierra Leone had already reached 16.5 percent. In the longer term, the model predicts a return of inflation to a level of about 12 percent, which corresponds to the model estimate of underlying inflation (i.e., the deterministic component of inflation in our model).

\section{Conclusion}

Our VAR modeling approach has proved useful for analyzing and forecasting inflation in Sierra Leone. It does not incorporate fiscal dominance for monetary policy because of data limitations, but the impulse-response functions show generally plausible economic responses to structural shocks. Variance decomposition showed which shocks account most for inflation variability, and the estimated deterministic component of the historical decomposition provides useful guidance for forecasting inflation by proxying underlying 
inflation. The stochastic component rounds out the picture by attributing changes in inflation to specific shocks.

We believe this method may prove useful in the analysis and forecast of inflation for other countries that also suffer from data limitations by providing statistical underpinning for inflation analysis. 


\section{Appendix}

\section{Diagnostic Test Results}
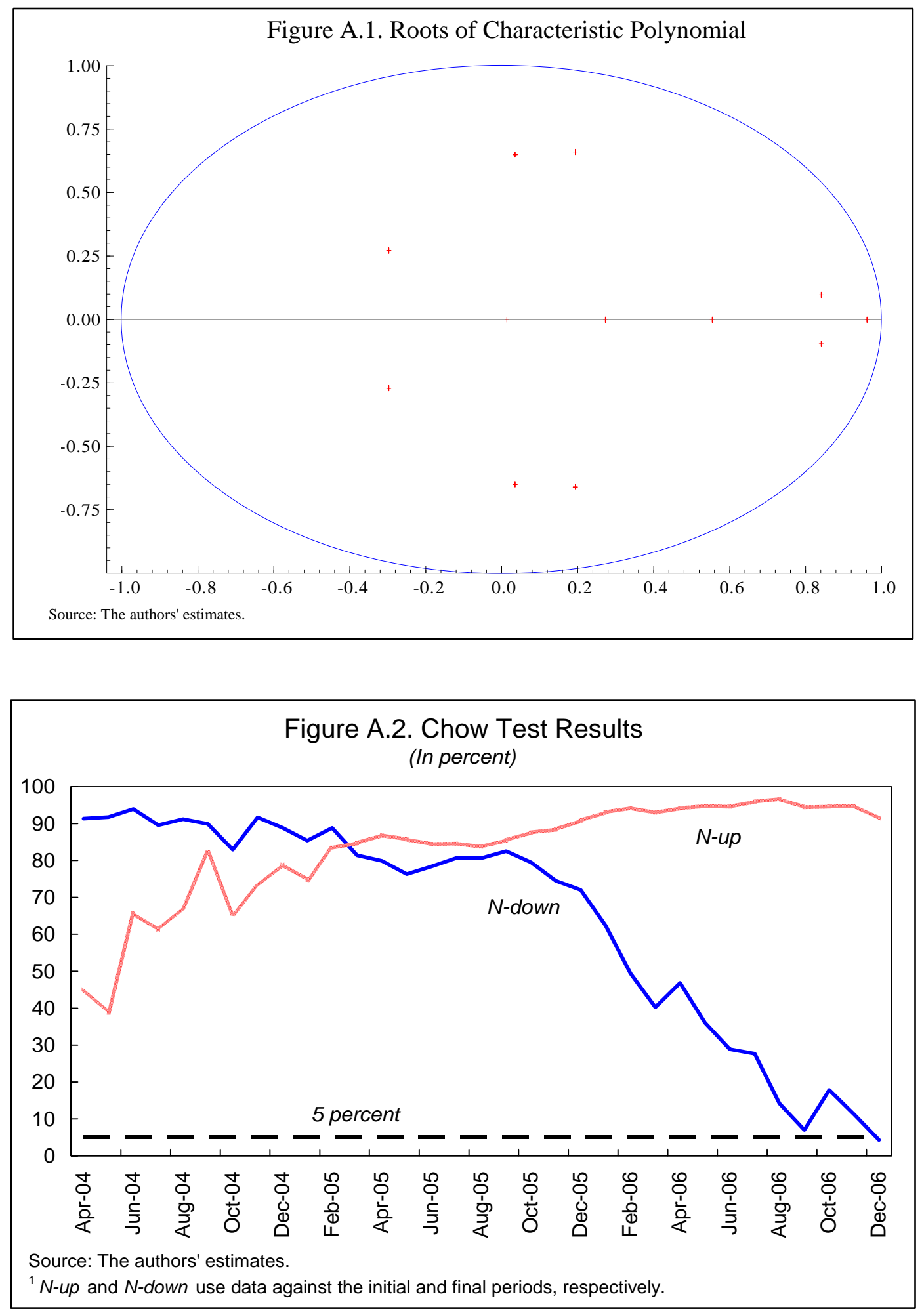
Figure A.3 - Cumulative Impulse Response Functions Response to Oil Price Shock

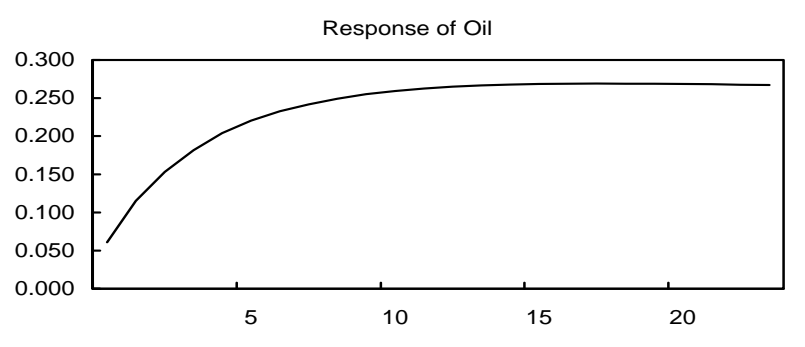

CPI Response
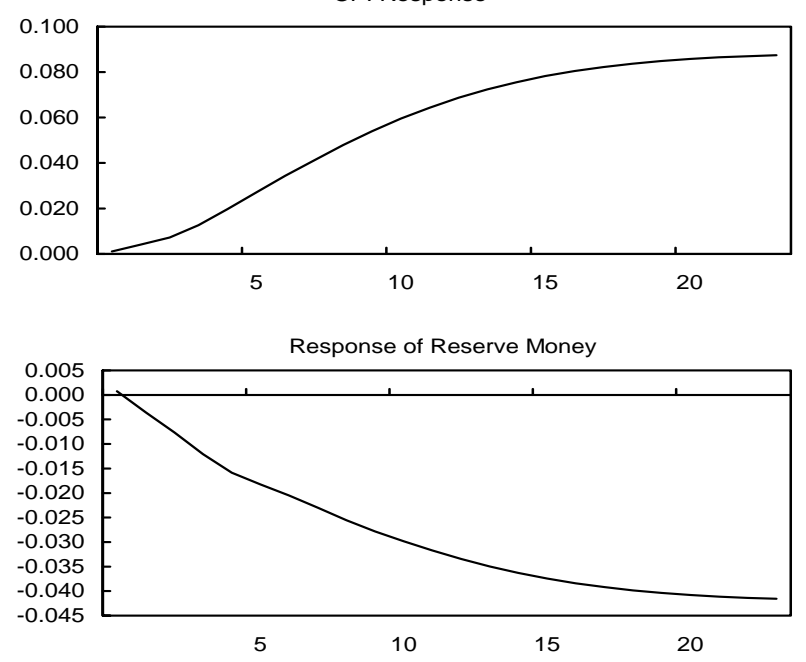

Exchange Rate (Le/US\$) Response

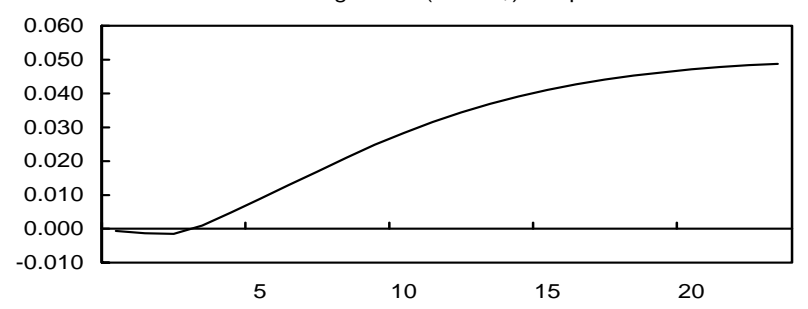

Real Exchange Rate Response
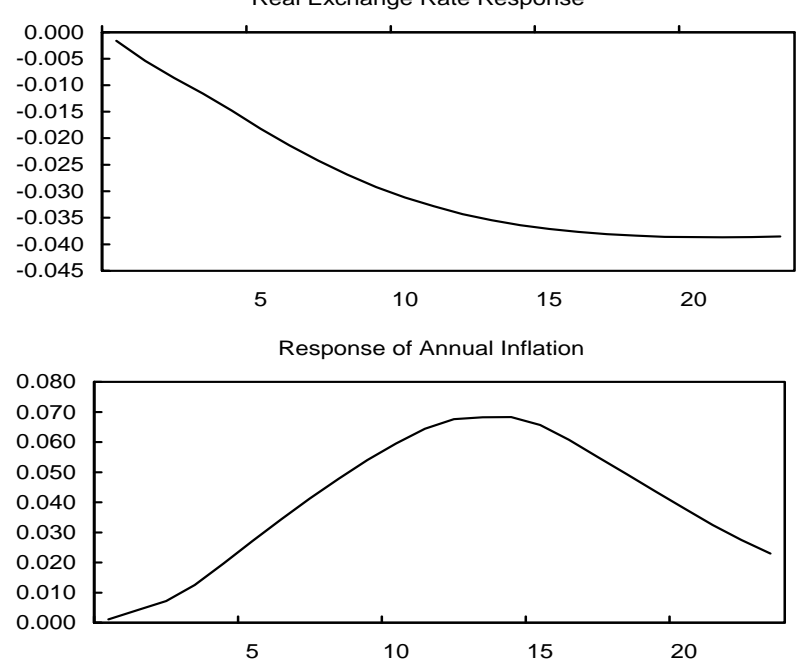


\begin{tabular}{|c|c|c|}
\hline Lags & LM-Stat & P-value \\
\hline 1 & 34.03 & 0.005 \\
\hline 2 & 39.01 & 0.001 \\
\hline 3 & 30.93 & 0.014 \\
\hline 4 & 21.93 & 0.146 \\
\hline 5 & 21.90 & 0.147 \\
\hline 6 & 19.47 & 0.245 \\
\hline 7 & 8.52 & 0.932 \\
\hline 8 & 18.17 & 0.314 \\
\hline 9 & 12.94 & 0.677 \\
\hline 10 & 19.56 & 0.241 \\
\hline 11 & 12.67 & 0.697 \\
\hline 12 & 19.53 & 0.242 \\
\hline 13 & 13.52 & 0.634 \\
\hline
\end{tabular}

Source: The authors' calculation.

${ }^{1}$ The null hypothesis is no serial correlation at lag order $\mathrm{h}$.

Table A.2. VAR Residual Normality Tests ${ }^{12}$

\begin{tabular}{cccc}
\hline Component & Jarque-Bera & df & P-value \\
\hline 1 & 2.18 & 2 & 0.336 \\
2 & 2.01 & 2 & 0.367 \\
3 & 4.59 & 2 & 0.101 \\
4 & 1.17 & 2 & 0.556 \\
Joint & 9.95 & 8 & 0.268 \\
\hline
\end{tabular}

Source: Author's calculations.

${ }^{1}$ Cholesky (Lutkepohl) is used for orthogonalization.

${ }^{2}$ The null hypothesis is that residuals are multivariate normal.

Table A.3. White Residual Heteroskedasticity Tests $^{1}$

\begin{tabular}{|cccc|}
\hline & Chi-sq & df & P-value \\
\hline No cross terms & 324.48 & 260 & 0.004 \\
\hline
\end{tabular}

Source: Author's calculations.

${ }^{1}$ The null hypothesis is no heteroskedasticity in the data. No cross terms. 


\section{References}

Blanchard, Olivier, and Danny Quah, 1989, “The Dynamic Effects of Aggregate Demand and Supply Disturbances,” American Economic Review Vol. 79 (4), pp. 655-673.

Calvo, Guillermo, and Carmen Reinhart, 2002, “Fear of Floating,” Quarterly Journal of Economics Vol. 117 (2), pp. 379-408.

Catalán, Mario, and Ruy Lama, 2006, “Fiscal Policy and External Balance in Spain,” IMF Country Report No. 06/213 (Washington: International Monetary Fund).

Cheng, Kevin C., 2006, “A VAR Analysis of Kenya's Monetary Policy Transmission Mechanism: How Does the Central Bank’s REPO Rate Affect the Economy?” IMF Country Report No. 06/300 (Washington: International Monetary Fund).

Christiano, Lawrence, Martin Eichenbaum, and Charles Evans, 1999, “Monetary Policy Shocks: What Have We Learned and to What End?” in Handbook of Macroeconomics, ed. by John B. Taylor and Michael Woodford. Vol. 1A, pp. 65-148 (North Holland: Elsevier).

Kallon, Kelfala M., 1994, “An Econometric Analysis of Inflation in Sierra Leone,” Journal of African Economies, Vol. 3 (2), pp. 199-230.

Kim, Soyoung, 1999, “Do Monetary Policy Shocks Matter in the G-7 Countries? Using Common Identifying Assumptions About Monetary Policy Across Countries,” Journal of International Economics, Vol. 48, pp. 387-412.

, and Nouriel Roubini, 2000, "Exchange Rate Anomalies in the Industrial Countries: A Solution With a Structural VAR Approach,” Journal of Monetary Economics, Vol. 45, pp. 561-86. 
Kovanen, Arto, 2006, "Why Do Prices in Sierra Leone Change So Often? A Case Study Using Micro-Level Price Data,” IMF Working Paper 06/53 (Washington: International Monetary Fund).

Krueger, Anne, 1991, “Issues in Policy Reform in Developing Countries,” Special Lecture at the $61^{\text {st }}$ Annual Meeting of the Southern Economic Association (Nashville: Tennessee).

Kuijs, Louis, 2002, “Monetary Policy Transmission Mechanisms and Inflation in Slovakia,” IMF Working Paper 02/80 (Washington: International Monetary Fund).

Mwase, Nkunde, 2006, “An Empirical Investigation of the Exchange Rate Pass-Through to Inflation in Tanzania,” IMF Working Paper 06/150 (Washington: International Monetary Fund).

Pattillo, Catherine, Helene Poirson, and Luca Ricci, 2002, “External Debt and Growth,” IMF Working Paper 02/69 (Washington: International Monetary Fund).

Sims, Christopher A., 1972, “Money, Income, and Causality,” American Economic Review, Vol. 62 (4), pp. 540-52. , 1980, “Comparison of Interwar and Postwar Business Cycles: Monetarism Reconsidered,” American Economic Review, Vol. 70 (2), pp. 250-57. , and Tao A. Zha, 1998, “Does Monetary Policy Generate Recessions?” Federal Reserve Bank of Atlanta Working Paper 98-12.

Stavrev, Emil, 2005, “Macroeconomic Implications of Domestic Credit in Latvia,” IMF Country Report No. 05/277 (Washington: International Monetary Fund). 
Svensson, Lars, 1998, “Open-Economy Inflation Targeting,” NBER Working Paper 6545 (Cambridge, Massachusetts: National Bureau of Economic Research).

Tucker, Joseph Ansu, 2004, “The Stability of Money Demand in the West African Monetary Zone-Implications for the Conduct of a Single Monetary Policy,” Bank of Sierra Leone Bulletin, July-December 2004 (Freetown: Bank of Sierra Leone). 